\title{
How much energy will your NGN consume? A model for energy consumption in next generation access networks: The case of Spain
}

\author{
Rafael Coomonte , Claudio Feijóo , Sergio Ramos , José-Luis Gómez-Barroso
}

\begin{abstract}
A B S T R A C T
The contribution to global energy consumption of the information and communications technology (ICT) sector has increased considerably in the last decade, along with its growing relevance to the overall economy. This trend will continue due to the seemingly ever greater use of these technologies, with broadband data traffic generated by the usage of telecommunication networks as a primary component. In fact, in response to user demand, the telecommunications industry is initiating the deployment of next generation networks (NGNs). However, energy consumption is mostly absent from the debate on these deployments, in spite of the potential impact on both expenses and sustainability. In addition, consumers are unaware of the energy impact of their choices in ultra-broadband services. This paper focuses on forecasting energy consumption in the access part of NGNs by modelling the combined effect of the deployment of two different ultra-broadband technologies (FTTH-GPON and LTE), the evolution of traffic per user, and the energy consumption in each of the networks and user devices. Conclusions are presented on the levels of energy consumption, their cost and the impact of different network design parameters. The effect of technological developments, techno-economic and policy decisions on energy consumption is highlighted. On the consumer side, practical figures and comparisons across technologies are provided. Although the paper focuses on Spain, the analysis can be extended to similar countries.
\end{abstract}

\section{Introduction}

Many sustainability challenges pervade the planet-so much so that the topic of sustainability is playing an increasingly important role as a factor in corporate and consumer decisions. "Green consumption" attitudes and habits are developing as part of more socially conscious behaviour. Businesses are becoming more aware of this trend and are adapting their strategies accordingly. Other factors-norms, taxes on pollution, and even company values-also oblige them to consider sustainability. In fact, according to Murugesan (2008), “ investors and consumers are beginning to demand more disclosures from companies with regard to their carbon footprint as well as their environmental initiatives and achievements, and they have started discounting share prices of companies that poorly address the environmental problems they create." 
Do the same "green" rules apply in any market segment? The answer, obviously, is no. First, real or perceived environmental impacts differ across industries; any consistency in consumption behaviour is difficult to measure. The same green consumer will not use the same information sources or decision-making criteria, consider the same options, or focus on the same industry actors for products in different sectors (McDonald, Oates, Thyne, Alevizou, \& McMorland, 2009).

Few studies related to these matters have been conducted in the telecommunications field. Røpke (2012) highlights that "although the integration of ICT in everyday life has considerable environmental impacts, this concern has played a very minor role in the research community studying people's use of ICT". One limited exception is the study by Ali, Rehman, Yilmaz, Nazir, and Ali (2010) of the cellular industry of Pakistan, which did not report any relationship between awareness of corporate social responsibility activities and consumer purchase intentions. Broadening the scope to any utility, the issue of green electricity tariffs has been subject to increasing analysis. Potential adopters are found to have higher incomes, be better informed with respect to energy matters, show concern for the environment, and believe that individual actions can make a difference in environmental degradation (Diaz-Rainey \& Ashton, 2011). However, Ozaki (2011) found that consumers sympathetic to environmental issues do not necessarily adopt green electricity, which may be due to the lack of strong social norms and personal relevance, the inconvenience of switching, uncertainty about the quality of green electricity and the lack of accurate information. Information is a recurring factor in these analyses, and it is indeed an important issue. In an experiment conducted by Stall-Meadows and Hebert (2011), when participants were informed about the energy efficiency, sustainability and associated costs of several lighting types, their preferences towards adopting higher-priced sustainable lighting grew considerably. The information technologies sector, which is similar to the telecommunications sector, has also been the subject of considerable activity in the definition of paths and guidelines for adoption of more sustainable practices (Murugesan, 2008), although again, there is a scarcity of quantitative references on the consumer perspective.

The above discussion shows that although environmental matters are far from being a hot topic in today's telecommunications markets, appropriately marketed "green strategies" may nonetheless be productive. For a mediumto long-term time horizon, this assertion could be reaffirmed, assuming that concerns about global, social and environmental well-being will increase. In this scenario, the role of consumers in the development of product innovation will be reinforced. The distribution of consumer preferences with regards to quality, price, and the environmental impact of consumption will determine whether newer, more environmentally benign paradigms are developed and are beneficial (Røpke, 2012) and whether these new paradigms will replace older, environmentally harmful technology paradigms (Windrum, Ciarli, \& Birchenhall, 2009). Moreover, large multinational corporations (as are many telecommunications operators) are regarded as playing a specific role in sustainable development-that they are part of the problem as well as the solution is increasingly recognised (Kolk \& van Tulder, 2010).

In spite of the evidence of these trends, the impact of energy consumption of next generation networks (NGNs) seems mostly absent from the analysis of their deployment and usage. In particular, the potential of upcoming ultra-broadband networks to make a significant contribution to reducing the carbon footprint of the ICT sector has been anticipated (ITU, 2008a) but never thoroughly examined, in spite of many authors predicting that broadband may become the most important public utility in the 21st-century economy (Melody, 2007; Røpke, 2012) and calling for research on this topic (Murugesan, 2008). In this regard, broadband has several main effects on energy consumption: its wider adoption would raise energy consumption but, at the same time, could positively change, in terms of energy, the processes of production, transport and consumption in many sectors-smart buildings, smart grids, smart transportation systems-while having mostly unknown systemic effects related to medium- or long-term adaptations of behaviour and economic structures that follow the services provided through broadband infrastructures (Røpke, 2012).

Although it is not the purpose of this paper to prove the contribution of NGNs to energy efficiency and sustainability, it is argued that it could be a potentially positive move for an operator to bring these issues to the forefront and increase efforts to achieve higher energy efficiency in its network operations. Active and informed customers may reward them with their loyalty, which has been shown to be stronger when customers believe that firms behave ethically (Valenzuela, Mulki, \& Jaramillo, 2010). In addition, it would attract those customers who not only consider functionality and price but also search for products that reflect their self-image and values. Of course, last but not least, given the impact of energy consumption on operators' operating expenses, as shown in this paper, energy savings would contribute considerably to profitability.

The energy consumption of NGNs is therefore something to be taken seriously. Some earlier approaches to address this topic have been presented in the technical literature. Baliga, Ayre, Sorin, Hinton, and Tucker (2008) provide a simple comparison of energy consumption across fibre-based technologies but did not consider network design, deployment or future evolution. Another limited attempt to establish a basic energy consumption calculation procedure was presented by Coomonte, Lastres, Feijóo, and Martin (2012), also for the access part of fibre-based networks. Unlike these previous efforts, in the present paper, in addition to the fibre-to-the-home (FTTH) Gigabit passive optical network (GPON) being considered specifically as the representative solution of the fixed technology choice, long-term evolution (LTE) is analysed, broadening the technology range to cover the mobile field and allowing for few existing comparisons between wired and wireless technologies. In addition, this paper introduces a realistic baseline for energy consumption, considering in detail the network deployment, the ultra-broadband adoption, the data demands of users, and the effects of improvements in both technology and the energy consumption of devices. The paper thus differs from previous attempts that included only considerations of steady-state static conditions. Moreover, analysis of the link between consumption of user devices and network usage is included in the paper, as this plays a significant role in consumers perspectives on energy. These issues have not been addressed in earlier works, as far as the authors are aware, let alone combined in a single comprehensive 
model. It is also worth mentioning that there is also an increasing number of technical papers aimed at very specific aspects of energy efficiency during network operation: for instance, Ajmone Marsan and Meo (2011) on energy saving when sharing wireless infrastructures, or López Vizcaíno, Ye, and Tafur Monroy (2012) on modulation techniques in fibre-based networks.

The overall purpose of this paper is to increase awareness of the energy and sustainability choices involved in ultrabroadband technology usage. To achieve this purpose, this paper presents a baseline for present and future energy consumption of FTTH-GPON and LTE as two main types of access networks, including the devices used in conjunction with the networks, and a simple sensitivity analysis with respect to selected design parameters. The paper models, in the baseline, the evolution over time of three primary forces: the consumption profiles of the diverse active devices involved in the network architecture, the users' data traffic patterns as they affect the network design and deployment, and the penetration and deployment of NGNs within the socio-economic scenario presented-that of Spain.

This paper only considers the access part of network and the operative part of its full life cycle. There are good reasons to constrain the analysis to these two dimensions. With respect to the access choice, the devices in this part of the network are estimated to consume, on average, 5 times less energy than the devices in the transport part, and almost 9 times less than the devices in the core network (Bolla, Bruschi, Davoli, \& Cucchietti, 2011). However, the number of devices in the access part of the network represents $94 \%$ of the total number of devices in the full network. Combined these two factors suggest that approximately $70 \%$ of total consumption takes place in the access network and that the remaining $30 \%$ is distributed in the core and transport layers (Shi, Chowdhury, \& Mukherjee, 2013). As a consequence, the analysis of the access part of the network appears more relevant. In addition, it is in the access part where the differences among technologies are significant, whereas the transport and core parts of networks are increasingly similar or shared between technologies. The operative part of the network life cycle is where energy is consumed to provide telecom services; thus, it is more relevant to the decisions of operators and users, and it accounts for the largest part of a network's environmental impact (Scharnhorst, Hilty, \& Jolliet, 2006). In fact, according to available studies, more than $50 \%$ of the total environmental impact of a network is associated with the operative part of the network's life cycle (Malmodin, Oliv, \& Bergmark, 2001).

After this introduction on the rationale and objective of this study, this paper is structured into the following sections. The next section describes the proposed model for the energy consumption of the two types of access networks considered: fibre-based and wireless. It closes with a longer subsection providing a middle-term projection-a baseline-of energy consumption for both. Section 3 presents and discusses the results obtained. The final section of the paper offers some conclusions and implications drawn from the analysis of the results.

\section{Energy consumption calculations and baseline model}

The assessment of energy consumption begins with the selection of the technologies and architectures for the access portion of the network. These, together with coverage and quality objectives, determine the number and type of active devices-that is, those consuming energy-in the network. In this section, the energy-related variables and the energy prices, as well as their reference values, are discussed. The network design parameters are considered in a separate sub-section. Once all the elements in the procedure have been introduced, the next sub-section presents a detailed description of the full calculation procedure, explaining the influence of each parameter. Then a short description of the specific demographic case of Spain completes the energy consumption calculation process is provided. In addition, a model for the calculation of the energy consumption of user devices is presented, as it is considered separately from network energy consumption, for reasons explained above. The final sub-section ends with a baseline model for energy consumption of NGNs in the 2020 horizon, where the evolution over time of the variables described in the calculation process is considered in detail.

\subsection{Choice of NGN technologies}

The baseline calculations consider two technologies: FFTH for fixed deployments and LTE terrestrial wireless technology for the deployment of $4 \mathrm{G}$ mobile networks.

FTTH technology uses optical fibre to connect subscribers at their premises with two-way transmission speeds of up to $100 \mathrm{Mbps}$ (Kramer, De Andrade, Roy, \& Chowdhury, 2012). Continuing improvements in fibre-optic equipment are focused on increasing these speeds without replacing the deployed fibre, creating a "future proof" NGN technology (Fibre to the Home Council Europe, 2012). The particular type of FTTH analysed here is the Gigabit Passive Optical Network (GPON). This technology was developed by the ITU-T in the G.984 series of Recommendations (ITU, 2008b). It represents the reference technology for point to multi-point deployments, providing a maximum rate of $2.5 \mathrm{Gbps}$ of bandwidth downstream and $1.25 \mathrm{Gbps}$ upstream, shared at most by 64 users (ITU, 2008b). The FTTH market went from 11 million connected homes at the end of 2006 to approximately 86 million at the end of 2011 -this represents $5 \%$ of all households worldwide and $14 \%$ of the total fixed broadband market (IDATE, 2012), of which 22\% were GPON connections. Asia dominates this market with roughly $70 \%$ of the total market share, with the remaining $30 \%$ split equally between the Americas and the Europe, Middle East and Africa (EMEA) region (Reading, 2011). Currently, the transition from copper to fibre access networks is well underway and will result in the replacement of most copper access networks over the next two decades.

LTE was labelled as 4G by the International Telecommunications Union in 2010 (ITU, 2010), which considered it the natural evolution of the primary $3 \mathrm{G}$ mobile communications standards. Rather than a specific technology, LTE is an evolving 
standard aimed at fulfilling-and eventually surpassing-the International Mobile Telecommunications-Advanced (IMTAdvanced) technical and operational requirements for $4 \mathrm{G}$ technologies specified by the ITU (ITU-R, 2008). In fact, the figures for LTE deployment worldwide prove the key role of this technology in the evolution of mobile telecommunication networks. After the pioneering system was launched by TeliaSonera in 2009 in Stockholm, the deployment of LTE networks has grown rapidly. As of March 2013, there were 156 commercial LTE networks deployed in 67 countries-figures that are forecast to increase to 244 networks in 87 countries by the end of 2013 (GSA, 2013). The total number of subscribers reached 70 million by the end of the fourth quarter of 2012. More than half of these are Verizon network subscribers in the US. In addition, more than 660 LTE-enabled user devices are available (more than two and a half times the figure in January 2012), confirming that manufacturers are gradually embracing the migration from $3 \mathrm{G}$ to $4 \mathrm{G}$.

\subsection{Network architecture and active devices}

The network architectures presented in Figs. 1 and 2 derive from deployment models used in previous studies to assess the costs in the rollout process of NGA networks (Coomonte et al., 2012; Feijóo, Gómez-Barroso, \& Ramos, 2011). The FTTH architecture is congruent with technical models of fixed fibre-based access networks (Kramer et al., 2012) and main fibre cost-related studies (Analysys Mason, 2008, 2009). The architecture for the mobile network is based on the evolved UMTS Terrestrial Radio Access Network (e-UTRAN) (3GGPP, 2012; Dahlman et al., 2006). In the case of LTE, it has been assumed that major changes with significant impact will not happen in the current cellular commercial architecture within the time period considered in this paper (up to 2020) in spite of promising proposals on mesh networks and software-defined radio (Raychaudhuri \& Mandayam, 2012).

These architectures will be used for both the energy consumption and cost calculations, thus becoming a common framework for comparisons of the energy consumption costs with regard to operating expenses, network design, and deployment strategies.

The main elements in the access part of the fibre architecture are explained. First, the connection with the transport layer is accomplished through a local exchange office in which the energy consumption takes place at the Optical Line Termination (OLT) device. The other primary energy consumption within the network occurs at the customer interface via Customer Premises Equipment (CPE), which utilises an Optical Network Termination (ONT). In the GPON architecture, one or more distribution points are placed in between these two extremes, splitting the signal and dispersing it among subscribers. These splitters, as passive devices, do not contribute to the energy consumption of the network, but their

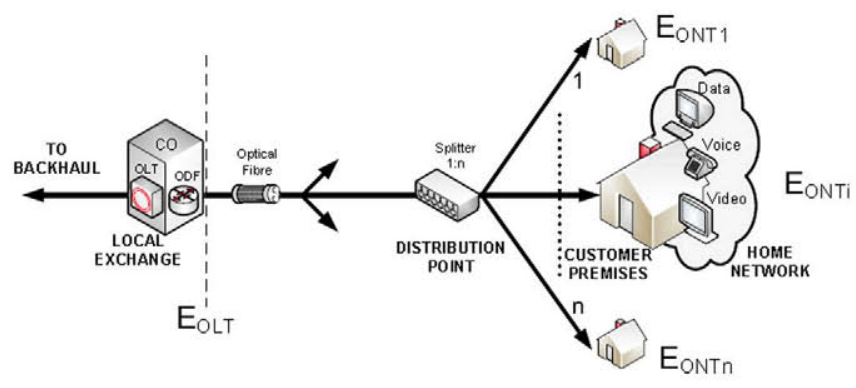

Fig. 1. FTTH network architecture.

Source: adapted from Coomonte et al. (2012).

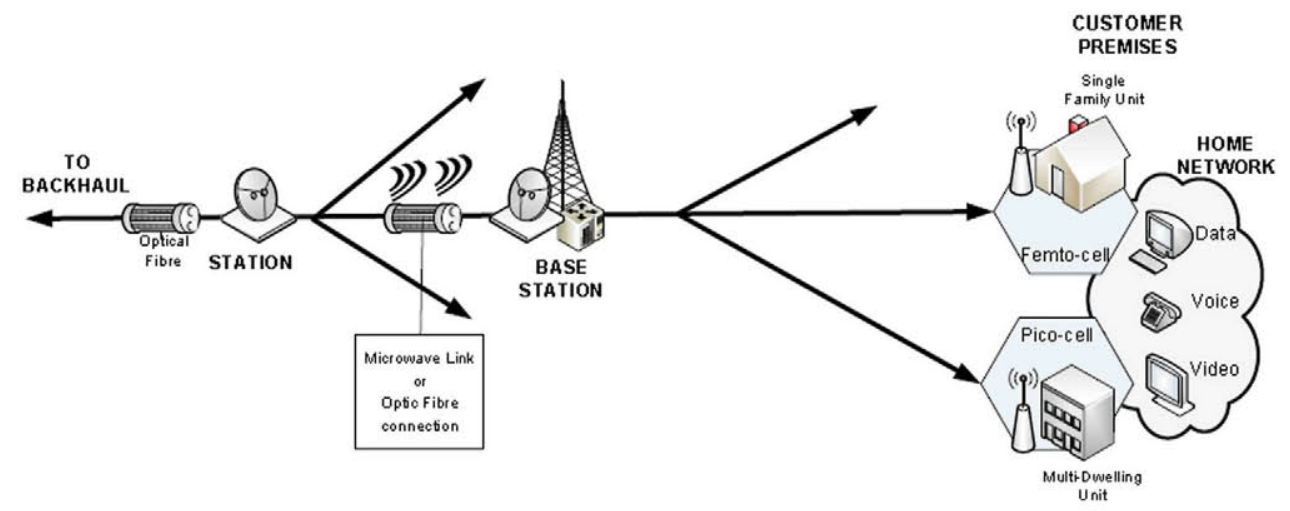

Fig. 2. 4G Mobile network architecture.

Source: adapted from Feijóo et al. (2011). 
number does affect the signal power level transmitted to and from the customer premises. Therefore, the energy consumed at the active devices (OLT and CPE) is typically higher than in other FTTH architectures such as Point to Point (PtP) (Keymile, 2011).

In the case of $4 \mathrm{G}$ networks, the active deployed devices consist of the base stations, the equipment to fill coverage gaps, and the equipment to interface with users devices. Base stations are the building blocks of any terrestrial wireless deployment, and the footprint of the network is composed of the coverage area of each base station. From an engineering perspective, the network deployment coincides with the selection of the most appropriate location of base stations, given the objectives of coverage and quality of communications (Andrews, Claussen, Dohler, Rangan, \& Reed, 2012; Schindler, Sadhir, Robbins, Guo, \& Paradis, 2011). In general, additional equipment is needed to fill coverage gaps due to the existence of physical obstacles to the radio waves emanating from the base stations. This typically occurs in urban areas. There are different types of equipment used depending on the size of the coverage gap-picocells have a coverage radius of hundreds of metres and femtocells tens of metres (Andrews et al., 2012; Ghosh et al., 2012). It is also the objective of both types of equipment to achieve or improve indoor coverage. In this paper, we will not distinguish between the two types of equipment and the number of them required, as the deployment of the network will be simply a function of the number of buildings in the area and not their size. As an additional simplification, base stations and pico-/femtocells are considered here as the equipment required for the connection of all types of user devices; not only handsets but also tablets, personal computers or connected television sets are not considered as such. Wi-Fi traffic off-loading from mobile networks into fixed networks is also considered as explained in the sections below.

\subsection{Energy consumption of active devices in the network}

For each of the active devices in the network, it is necessary to establish an energy profile. These behavioural functions determine the different levels of consumption for the devices according to the workload of the network. The profiles in this paper are defined in accordance to the values proposed in EC (2011) guidelines, the latest available, and which also suggest representative tiers for the next three years. It is worth noting that these values are merely recommendations for broadband equipment manufacturers and that actual consumption data will depart somewhat from these figures; however, they can be considered a representative depiction of the situation.

These profiles are shown in Fig. 3. The base station pattern is defined by consumption levels of $100 \%$ (high), $50 \%$ (medium) and 10\% (low or idle) load states, while the profiles of pico-/femtocells, OLT and ONT are only defined at the $100 \%$ (high) and 10\% (low or idle) load states. The low (or idle) state does not coincide with a switched-off power consumption level, as operations other than pure data transmission (for example, cooling) are necessary at all times. Due to this, these devices can never be shut down, even in cases of no transmission, as the reactivation process is not immediate, thereby affecting their real-time performance (Frenger, Moberg, Malmodin, Jading, \& Godor, 2011).

There are three main and mutually compatible ways of increasing the energy efficiency of networks with respect to active devices. The first is an architecture design aimed at reducing energy requirements. However, this is seldom undertaken, as network architectures are usually designed to fulfil specific coverage and service provision goals (Cuomo, Cianfrani, Polverini, \& Mangione, 2012). The second set of possible enhancements takes place at the system and network levels, in the definition of new functions, network management mechanisms and algorithms for dynamic resource management. These features are typically implemented at the software level and potentially upgraded and introduced into the network over the lifetime of several hardware generations. These potential improvements can be achieved, for instance, by using techniques to manage discontinuous transmission time slots during device operation (Frenger et al., 2011) or by analysing the network requirements and training the network to respond dynamically, putting specific sections to sleep (Cuomo et al., 2012; Shi et al., 2013). The third and most likely option is implemented at the device level, using the most up-to-date energy-efficient equipment either for new deployment or for replacement of existing equipment once the hardware amortisation has taken place. Technically, to achieve higher efficiency, the energy consumption profiles are

a

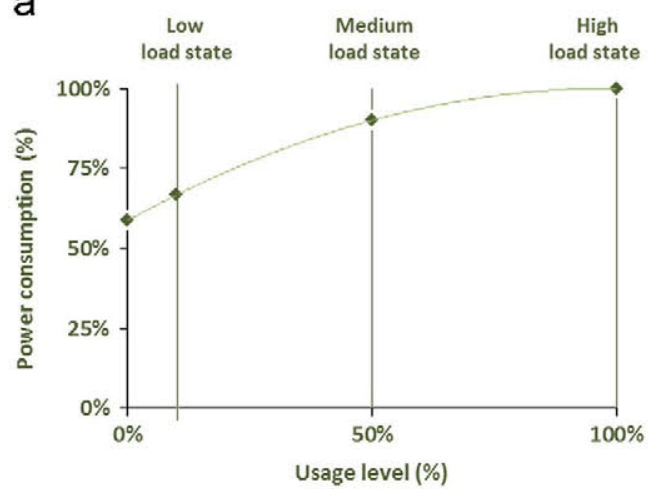

b

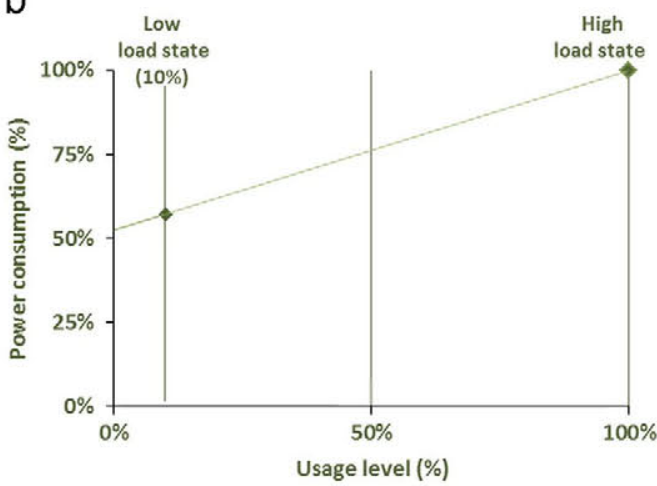

Fig. 3. Power consumption profiles for base stations (a) and pico-/femtocells, ONTs and OLTs (b). Based on the model from (Frenger et al., 2011) 
modified by lowering the level of power consumption at the $100 \%$ load state (maximum power consumption in absolute terms) or by adjusting the relative variation of the other states with respect to the maximum level of consumption. In this paper, both possibilities are combined in the suggested evolution for these patterns-see Section 2.1 .

In the analysis presented in this paper, only the last approach is considered in the baseline, as it is by far the most common procedure. Therefore, the most energy-efficient devices are included in the network deployment on a yearly basis. The devices already deployed are only replaced for more efficient ones after five years, which is the period assumed for device amortisation. The only exception takes place from 2017 onwards on mobile networks, where variations on the key design features of the network require a general replacement with new devices. This is explained later on. In the sensitivity analysis, alternative scenarios departing from the baseline are considered for possible improvements in management of networks as well as other roadmaps for achieving energy efficiency in network devices.

In any case, the actual energy consumption of the active devices at any given time depends on the data traffic workload (level of usage) of the network. The data traffic pattern in fibre networks has been analysed by Shi et al. (2013); suggesting, for example, that an hourly basis is enough to build a reasonable model for dynamic resource allocation. To avoid the difficulties of a dynamic model, a simpler approach reduces the problem to the consideration of an average hour-by-hour daily traffic evolution. A pattern of average daily usage of a network is presented in Fig. 4. This pattern was developed within the March Project (CELTIC-Plus, 2011) and is considered representative of the typical daily pattern, encompassing the variations across the different zones where the network is deployed as well as along different time frames of the year (days of the week, months, seasons, etc.). The combination of this pattern with the energy profile already presented permits the determination of the average energy consumed every hour throughout the day by the active devices and thus the daily average and total yearly consumptions.

\subsection{Energy prices}

For cost calculations, the price of the energy was obtained from EUROSTAT data on the electricity prices for industrial consumers in Spain. The price for 2012 was $0.1152 € / \mathrm{KWh}$. Forecasts of energy prices suggest an increase of $50 \%$ by 2030 compared to 2005 levels (EC, 2009, 2010b). This projected increase corresponds to an average annual increase of $2 \%$ at constant prices. The complete evolution in the energy prices used for reference is shown in Table 1.

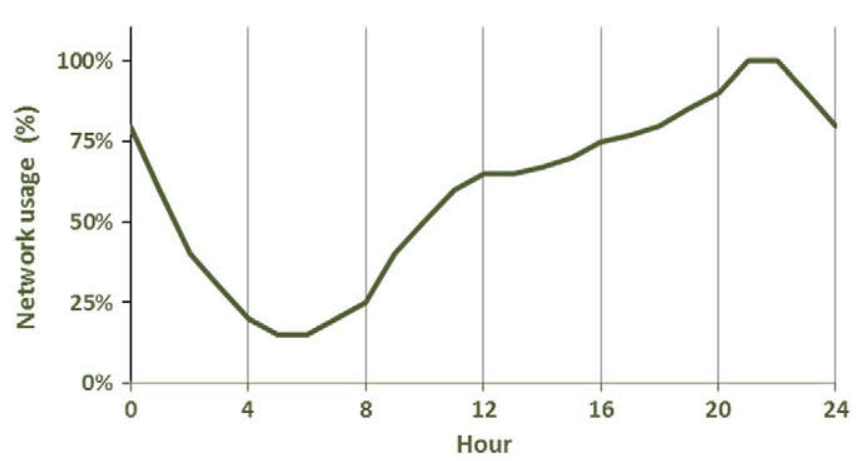

Fig. 4. Average daily network usage profile.

Source: March Project (CELTIC-Plus, 2011).

Table 1

Energy prices annual reference values.

\begin{tabular}{lll}
\hline Year & Energy price $(\boldsymbol{\ell} / \mathbf{K W h})$ & Details \\
\hline 2012 & 0.1152 & EUROSTAT data for the electricity prices for industrial consumers for the country of Spain \\
2013 & 0.118 & Estimations based on a constant $2 \%$ annual increase (with the 2012 value as reference) \\
2014 & 0.120 & \\
2015 & 0.122 & \\
2016 & 0.125 & \\
2017 & 0.127 & \\
2018 & 0.130 & \\
2019 & 0.132 & \\
2020 & 0.135 & \\
\hline
\end{tabular}




\subsection{Network design parameters}

According to the typical engineering design approach (Forsgren \& Prytz, 2006), the key network parameters are data traffic per user, quality of service, the (expected) penetration of each broadband technology, data throughput (data capacity) of local exchanges and base stations, and for mobile technologies the frequency of operation and the amount of spectrum bandwidth allocated to the operator. The sizing of the network depends on all of these parameters and, therefore, so does the energy consumption of the network. Each of these parameters is briefly discussed below, leaving the calculation process to be addressed in the following sub-section.

Data traffic has undoubtedly experienced significant increases in recent years, with global figures up to 43 Exabytes (EB) per month in 2012 and a forecasted compounded annual growth rate (CAGR) of 29\% for the period 2011-2016, reaching 110 $\mathrm{EB} /$ month in 2016 (CISCO, 2012a). Mobile traffic is expected to grow at rates of over 50\% until 2020, increasing from 1.3 $\mathrm{EB} /$ month in 2012 to approximately $40 \mathrm{~EB} /$ month in 2020 (Jefferies, 2011). Mobile traffic off-loaded via Wi-Fi was $9 \mathrm{~EB}$ per month in 2012 and is expected to grow to $18 \mathrm{~EB}$ per month at a CAGR of $21 \%$ (CISCO, 2012a). These figures show how users are changing their habits with regard to broadband, particularly with respect to their increasing usage of data-intensive applications such as social networks, cloud computing and various video services and applications. However, while these figures provide an aggregated average of user behaviour, they do not provide information about their concrete demands at (peak) data rates for specific services and applications. From a technical perspective, GPON technology is expected to be able to provide peak data rates of up to $2.5 \mathrm{Gbps}$, while expected LTE peak data rates range up to $150 \mathrm{Mbps}$. These two figures seem well above current prospects of (peak) user behaviour, whatever the combination of advanced services and applications they choose, and they are also well above main policy objectives set in the range of $100 \mathrm{Mbps}$ for 2020 (EC, 2010a).

In between average and peak data rates, the amount of time a given data rate is guaranteed for users-or the number of users than can be served simultaneously at a given data rate-is specified by the quality of service (QoS). In fact, QoS is arguably the design parameter that most affects the deployment of a network and, therefore, its energy consumption. While QoS levels are currently considered to be low, especially in mobile networks (Ixia, 2011; Vadada, 2010), it is expected that the evolution in the demand of higher speeds will be in accordance with an increase in the standards of QoS offered to users. In this paper, the starting point for the guaranteed data rate per subscriber is established initially at $30 \mathrm{Mbps}$ in fixed networks and $1 \mathrm{Mbps}$ in mobile networks. These are reference values for each technology that cover the current needs for more demanding data applications (Jukan \& Mambretti, 2012; Radio, Ying, Tatipamula, \& Madisetti, 2012).

Broadband penetration determines both the total number of potential subscribers and, along with the demographic scenario and the network deployment strategy, the number of them located in each area. The fixed broadband penetration in January 2012 was $81.1 \%$ of the premises, on average, in the EU (EC, 2012). Of this value, only $7.2 \%$ of the lines provide speeds of $30 \mathrm{Mbps}$ or above. A typical target for the prospective market saturation level of fixed broadband technology is set at $80 \%$ penetration in premises (Analysys Mason, 2008). Regarding mobile technologies, while the level of adoption of mobile services in general is over $100 \%$ in most developed countries, the specific penetration of mobile broadband (3G and beyond) is still relatively low: 43\% in January 2012 (EC, 2012). Most market prospects assign 4G figures approaching $80 \%$ of the population by 2020 (Jefferies, 2011). Once the number of potential subscribers is determined, an operator can follow different strategies for the deployment of the network, essentially using different combinations for the number of users in different areas to achieve an overall target. In general, as deployment costs per user are inversely related to population density (Tselekounis, Maniadakis, \& Varoutas, 2012), the most rational strategy for the operator to follow would be to start the deployment in those areas with higher population densities. However, this is not always the case, primarily as a consequence of diverse types of regulatory conditions.

The data throughput of a FTTH-GPON local exchange is dependent on the number of OLT cards and the splitting ratio in the GPON architecture. In this paper, a conservative scheme of two levels of splitting $-8 \times 8$ - has been preferred (Analysys Mason, 2008; Bock et al., 2008). This implies that each feeder fibre from the local exchange serves 64 customers supplying a maximum data rate per user of $30 \mathrm{Mbps}$ downstream and $19.5 \mathrm{Mbps}$ upstream. Higher data rates require the replacement of OLT cards and splitters to work with $10 \mathrm{Gbps}$ feeder fibres, the next step in GPON technology. In extreme rural areas a lower splitting ratio has been used as indicated in Table 2 due to the reduced number of potential subscribers.

In the case of mobile networks, frequencies allocated to the operator impact both the coverage and maximum throughput (the total data capacity) of each base station-the lower the frequency of operation, the greater the coverage, and the higher is the bandwidth, the higher is the throughput of the base station. Base station coverage is delimited by the lesser of two factors. The first is the share of the maximum throughput among the users while complying with QoS

Table 2

FTTH-GPON network sizing.

\begin{tabular}{|c|c|c|c|c|c|c|c|c|c|c|}
\hline Zone & $I$ & II & III & IV & $v$ & ИІ & VII & VIII & $I X$ & $x$ \\
\hline Number of users per access area & 16,384 & 16,384 & 16,384 & 16,384 & 16,384 & 16,384 & 4096 & 2048 & 512 & 256 \\
\hline Minimum number of fibres at the exchange & 256 & 256 & 256 & 256 & 256 & 256 & 64 & 32 & 8 & 8 \\
\hline Total splitter ratio & $8 \times 8$ & $8 \times 8$ & $8 \times 8$ & $8 \times 8$ & $8 \times 8$ & $8 \times 8$ & $8 \times 8$ & $8 \times 8$ & $1 \times 8$ & $1 \times 4$ \\
\hline
\end{tabular}


requisites. This limitation varies inversely with population density. The second derives from signal transmission losses. Beyond a certain distance, the signal is compromised with excessive errors. A typical maximum coverage radius at mobile communications lower frequencies ranges up to $50 \mathrm{~km}$ (Astely et al., 2009; Furuskar, Jing, Blomgren, \& Skillermark, 2011). However, this value diminishes to just a few $\mathrm{km}$ in areas of high building clustering or complex terrain, where the combination of diffraction and multipath interference significantly increases signal losses and errors. In any case, for mobile broadband the first limiting factor occurs usually in high (urban) and medium (suburban) population density zones, while the latter is typical of low population density zones (rural). As a consequence of the above, lower frequencies of operation (such as those resulting from the digital dividend) do not increase network coverage if the limiting factor is QoS.

The data throughput of a mobile base station depends, in addition to the bandwidth allocated to the operator, on the spectral efficiency level and on vendor-dependent parameters, such as the number of sectors and the number of channels for data transmission. Bandwidth allocation is subject to regulatory constraints due to the scarcity of the spectrum in more convenient frequency bands. In LTE technology, a typical value for this parameter is currently $20 \mathrm{MHz}$ (IDATE, 2012), although higher values will be required to satisfy the increasing demands of users as discussed in the next section. The spectral efficiency determines the capacity of using each unit of frequency available in the allocated bandwidth to transmit at a specific data rate. It is measured in bits per second per Hertz. A typical peak value for this parameter in LTE is $15 \mathrm{bps} / \mathrm{Hz}$ (IDATE, 2012), achieved close to base stations. As the paper assumes a very dense cellular network it is used as a reference value. The number of channels and sectors refers to the configuration on base stations. A typical LTE configuration features 3 sectors (each covering a $120^{\circ}$ angle) and a $2 \times 2 \mathrm{MIMO}^{1}$ (the one used in this model) or a $4 \times 4 \mathrm{MIMO}$ (Deruyck, Tanghe, Joseph, \& Martens, 2011) channel configuration. Considering the above parameters, a baseline base station could manage a total data throughput of up to $1800 \mathrm{Mbps}$.

\subsection{Demographic scenario}

The baseline is placed in the specific demographic framework of Spain (see Table 3 for details). Aside from the direct relevance of the case for Spain as a European example of NGN deployment, it is interesting to note that data for Spain is relatively similar to the "Euroland" scenario (Forge, Blackman, \& Bohlin, 2005), thus enabling its easy extension for similar countries.

The demographic framework classifies each of more than 8000 municipalities into 10 different geographical zones based on their population density. While other studies (Analysys Mason, 2009; Forge et al., 2005; Gómez-Barroso and RoblesRovalo, 2008; Jeanjean, 2010) typically divide the territory into 3 to 8 zones, this division into 10 zones allows for more accurate estimations in the "grey" areas with intermediate population densities, a key aspect of NGN deployment ( GómezBarroso \& Feijóo, 2010). However, and despite the increased granularity, this approach delivers little information on building clustering. Information on which part of a municipality is densely built and which has only scattered buildings allows for a more precise characterisation of suburban and rural areas. This is a key element for the proper dimensioning of networks, as base stations and local exchanges need to be located in a denser pattern in those places where buildings are also more densely placed. Therefore, to improve the approach, each density zone is further divided into two different sub-geotypes. In particular, a zone is classified into the "a" geotype if over $80 \%$ of its surface is covered with buildings. Otherwise, it is classified into the "b" geotype. Therefore, each zone has a share of "a" and "b" geotypes, except for the IX and X density zones that only contain the "b" type, as a result of their rural nature. This results in a total of 18 zones. Note that in fixed networks, the local exchanges in "b" geotypes require longer fibres to reach customers, and in rural areas, they use a reduced number of OLT cards and splitters with regard to a regular situation. For mobile networks, the share of "a" geotypes in each zone defines the number of femtocells required to complete the coverage of base stations. Additionally, due to the terrain in rural areas in Spain, a maximum coverage radius of $10 \mathrm{~km}$ is assigned for a base station in those areas when there is no other limiting factor.

\subsection{Calculation process}

The calculation process is designed from the bottom up following the traditional engineering design approach (Forsgren \& Prytz, 2006), and consists of two main parts. The first determines the size-the footprint-of the basic coverage unit for each technology (the local exchange access area for fixed networks and cell for mobile networks) and the number needed in the different zones that compose the demographic scenario. In the second part, the per-hour average, daily average and yearly energy consumption of the access network are determined by applying the energy profiles of the active devices combined with the network usage. The process is explained in detail below.

Starting with mobile networks, calculation begins with the size of the cell, in terms of both the area covered and the maximum number of subscribers. The latter (see Eq. (1)) is calculated from the relationship between the total data throughput per base station and the specified QoS. This maximum number of subscribers is then compared with the size of

\footnotetext{
${ }^{1}$ MIMO (Multiple Input Multiple Output) is a technology that makes use of antenna arrays with smart signal-processing algorithms at both the transmitter and receiver to improve communication performance. The notation IxO (i.e. $2 \times 2,4 \times 4$ ) determines the number of input and output radio channels carrying the signal, not the physical antenna devices.
} 
Table 3

Spanish demographic data.

Source: INE (Spanish Statistics Institute) demographic database.

\begin{tabular}{|c|c|c|c|c|c|c|c|c|c|c|c|}
\hline Zone & $I$ & II & III & IV & $V$ & VI & VII & VIII & IX & $\boldsymbol{X}$ & Total \\
\hline $\begin{array}{l}\text { Density (inhabitants per } \\
\text { square } \mathrm{km} \text { ) }\end{array}$ & $>10,000$ & $10-5000$ & $5-3000$ & $3-1000$ & $\begin{array}{l}1000- \\
500\end{array}$ & $500-100$ & $100-50$ & $50-10$ & $10-5$ & $<5$ & \\
\hline $\begin{array}{l}\text { Number of } \\
\text { municipalities }\end{array}$ & 17 & 28 & 46 & 175 & 209 & 946 & 745 & 2705 & 1444 & 1797 & 8112 \\
\hline $\begin{array}{l}\text { Share of total } \\
\text { population (\%) }\end{array}$ & $5.79 \%$ & $13.48 \%$ & $8.20 \%$ & $18.39 \%$ & $10.73 \%$ & $24.23 \%$ & $7.65 \%$ & $9.43 \%$ & $1.43 \%$ & $0.67 \%$ & $100 \%$ \\
\hline Geotype A share (\%) & $85 \%$ & $63 \%$ & $70 \%$ & $38 \%$ & $21 \%$ & $31 \%$ & $56 \%$ & $43 \%$ & $0 \%$ & $0 \%$ & \\
\hline Geotype B share (\%) & $15 \%$ & $37 \%$ & $30 \%$ & $62 \%$ & $79 \%$ & $69 \%$ & $44 \%$ & $57 \%$ & $100 \%$ & $100 \%$ & \\
\hline Number of users & $2,707,360$ & $6,300,119$ & $3,832,203$ & $8,596,709$ & $5,016,333$ & $11,326,891$ & $3,574,008$ & $4,406,394$ & 668,735 & 317,055 & $46,745,807$ \\
\hline Number of premises & 963,482 & $2,090,404$ & $1,185,622$ & $2,575,576$ & $1,446,293$ & 3190.138 & $1,061,590$ & $1,453,938$ & 258,753 & 134,524 & $14,360,318$ \\
\hline Number of buildings & 150,991 & 349,457 & 292,268 & $1,009,798$ & 796,835 & $2,511,879$ & $1,195,232$ & $2,089,301$ & 515,673 & 373,573 & $9,285,007$ \\
\hline $\begin{array}{l}\text { Ratio users per butilding } \\
\left(\boldsymbol{r}_{\text {user-building }}\right)\end{array}$ & 21.70 & 21.81 & 15.87 & 10.30 & 7.62 & 5.46 & 3.62 & 2.55 & 1.57 & 1.03 & \\
\hline
\end{tabular}

Table 4

$4 G$ network sizing.

\begin{tabular}{|c|c|c|c|c|c|c|c|c|c|c|c|}
\hline Zone & I & II & III & IV & $V$ & $V I$ & VII & VIII & $I X$ & $X$ & Total \\
\hline Number of cells & 7376 & 17,185 & 10,487 & 23,542 & 13,870 & 31,765 & 10,884 & 15,202 & 3973 & 4218 & 42,105 \\
\hline Number of users per cell ( $\left.n_{u s e r c e l l}\right)$ & 360 & 360 & 360 & 360 & 360 & 360 & 360 & 360 & 223 & 106 & \\
\hline Area of the cell & 0.05 & 0.15 & 0.24 & 0.59 & 1.41 & 4.56 & 14.28 & 36.71 & 64.36 & 60.42 & \\
\hline Radius of the cell & 0.13 & 0.22 & 0.27 & 0.43 & 0.67 & 1.21 & 2.13 & 3.42 & 4.53 & 4.39 & \\
\hline Number of areas per zone & 160 & 373 & 227 & 508 & 297 & 670 & 845 & 2083 & 1265 & 1199 & 7627 \\
\hline Number of users per area & 16384 & 16384 & 16384 & 16384 & 16384 & 16384 & 4096 & 2048 & 512 & 256 & \\
\hline Number of cells per access area & 46.10 & 46.07 & 46.20 & 46.34 & 46.70 & 47.41 & 12.88 & 7.30 & 3.14 & 3.52 & \\
\hline
\end{tabular}

the municipality. If it is lower, then the size of the cell is calculated as the size of the area covering that number of subscribers, given the population density of the zone under consideration. The number of cells in the municipality is rounded up to the nearest integer to cater to the remaining fraction of users not covered (the worst-case design). In contrast, if the maximum number of subscribers is greater than the population of the municipality, the maximum number of subscribers will be limited by the population of the municipality, and the cell size is the maximum range of coverage at the frequency of operation. If the range of the cell is smaller than the size of the municipality, then the location of premises in the municipality is used to check the required number of cells. If the range of the cell is greater than the size of the municipality and there are no geographic obstacles (a rare situation in Spain), then the population of the neighbouring municipality is also considered for cell coverage. Although this simplified process may slightly over-estimate the number of base stations required, it also reflects the reality concerning licences for base station sites, which are usually granted at the municipal level. It is, therefore, considered a reasonable depiction of a real deployment situation for mobile networks. Table 4 presents the resulting number of potential subscribers per base station across the different demographic zones. The number of femtocells per cell is also obtained at this stage from the percentage of urban buildings with respect to the total number of premises in the average municipality in the zone.

$$
n_{\text {users }}=\frac{\text { Total data throughput }}{\text { QOS }(\text { data rate per user })}=\frac{B W \times \text { Spectral efficiency } \times n_{\text {sec tors }} \times n_{\text {antennas }}}{\text { QOS }}
$$

For fixed networks, the calculation process is equivalent, using the local exchange access area instead of the cell area. The starting point is the number of potential subscribers covered by a local exchange. As the location of local exchanges are re-used from legacy networks, this value is already set, as indicated in Table 2 . The same comparisons as above with the population size of the municipality are considered. In the case of mobile networks, an access area is also calculated. The reason for adding this intermediate stage in the calculations for the deployment of a $4 \mathrm{G}$ network is derived from our interest in establishing a common framework for comparisons between mobile and fibre-based technologies with respect to the access part of the network. The base station topology is denser than that of local exchanges (their fibre-based "counterpart"), such that, to effectively reach subscribers, it is necessary to lay a certain amount of fibre (Fig. 2) from where an equivalent local exchange would be located. Therefore, using this fictitious "access area" permits the calculation of the additional fibre (the "middle mile") that must be deployed to reach the base stations in a $4 \mathrm{G}$ network. Thus, the inclusion of this value in the cost and energy calculations of the mobile access network creates a framework that is more comparable with fixed technologies.

Once the total number of access areas in each of the population density zones is calculated, operators may follow considerably different strategies for rolling out the network in each zone (as discussed above). The commercially simplest 
option was chosen for the baseline: the deployment starts in the highest-density zone and moves into subsequent zones until the coverage objective is achieved. The simple rationale behind this approach consists of decreasing the costs of deployment per potential subscriber as much as possible, as in this industry profitability is based on the average return per user. The deployment strategies used and their target levels of coverage are detailed in Table 5.

The second part of the calculation process considers the power required by the active devices in the network. The maximum energy reference levels of OLT, ONT and pico-/femtocells are constant. However, in the case of base stations, this level varies with the number of subscribers and, therefore, changes across zones. The combination of the energy profile of the devices with the network daily usage pattern allows for obtaining the percentage of power consumption regarding the maximum of each device for every hour of the day and its aggregation in the annual consumption. The process for the calculation of hourly, daily and annual energy consumption is illustrated in Fig. 5. Therefore, the energy consumption calculations for mobile and fixed networks show their primary differences in the first part of the process (Fig. 5a and b). The second stage of the procedure (Fig. 5c) is common for both types of networks, with the exception of using the appropriate device energy profile in each case.

\subsection{User devices energy consumption}

User devices are not strictly part of the access network. However, energy calculations from the consumer perspective would not be complete without their consideration. The analysis of the energy consumption of user devices differs from the compilation of the user device market in Spain, as presented in Table 6. The distribution of the devices across the demographic scenario was assumed to be proportional to the population and premises distribution.

Two basic operational modes are defined for user devices: continuous power consumption during usage and an idle state with energy consumption only while recharging the device. Therefore, Eq. (2) is used for the consumption per device.

$$
p_{\text {device }}^{\text {day }}=\left(t_{\text {usage }} \times p_{\text {usage }}\right)+\left(t_{\text {recharge }} \times p_{\text {recharge }} \times n_{\text {recharge }}\right)
$$

where $t_{\text {usage }}$ and $p_{\text {usage }}$ respectively are the average daily times of usage of the device in hours and the power in watts per hour consumed by the device, and $t_{\text {recharge }}, p_{\text {recharge }}$ and $n_{\text {recharge }}$ are respectively the times in hours required to completely recharge the device, the power consumed in watts per hour while performing this process and the number of average recharges per day. See Table 7 for the values of each parameter in 2011.

For energy consumption comparison purposes, laptops, computers and other devices are considered to belong to fixed networks, while tablets and smartphones are considered to belong to mobile access networks. The off-loading of mobile data traffic via Wi-Fi is considered to assign part of the consumption of mobile devices to fixed networks. Forecasts from the industry are used for off-loading traffic (CISCO, 2012a). The energy consumed in the router group is shared in proportion to the ratio of fixed and off-loaded mobile traffic to pure mobile data traffic (CISCO, 2012b).

\subsection{Model for the evolution of the energy consumption baseline}

Energy consumption of NGNs in the 2020 horizon depends on the evolution of some of the variables described in the previous section. In particular, this paper considers the evolution of technologies, user demands and devices (the combination of which is reflected in data traffic), the evolution of energy prices, the effects of the deployment progress of the networks and the increasing energy efficiency of devices. In the following paragraphs the evolution over time of each of these parameters is considered in detail.

Beginning with data traffic, an increment of guaranteed speeds is considered, in accordance with the increasing prevalence of broadband-intensive applications such as video, cloud computing, videogames, and, in the mobile domain, M2M and augmented reality. The objective figures for 2020 are set at $100 \mathrm{Mbps}$ for fixed networks and $5 \mathrm{Mbps}$ for mobile networks, in conjunction with policy (EC, 2010a) and current industrial perspectives (Jukan \& Mambretti, 2012; Radio et al., 2012). In particular, in fixed networks, the guaranteed data rate is assumed to increase from 30 Mbps to 50 Mbps by 2016 and to $100 \mathrm{Mbps}$ by 2020 . In mobile networks, a more nuanced evolution is assumed to take place, from $1 \mathrm{Mbps}$ to $2 \mathrm{Mbps}$ in 2013, to $3 \mathrm{Mbps}$ by 2015, and to $5 \mathrm{Mbps}$ by 2017. The corresponding CAGR of the guaranteed data rate for the period 2011-2020 for fixed networks is $13 \%$, while for mobile networks it is $17 \%$. Both figures are rather more conservative than the forecasts of aggregated data traffic growth presented in the previous section.

For mobile networks the achievement of these objectives requires a shift in two key design factors: spectral efficiency and allocated spectrum. Expecting a similar evolution from 3.5G to 4G technologies (Lluch, 2012) a shift from 15 to $20 \mathrm{bps} / \mathrm{Hz}$ is proposed for spectral efficiency. Regarding allocated spectrum to operators, a move from the initial $20 \mathrm{MHz}$ to $40 \mathrm{MHz}$ is also proposed. Both network design enhancements are assumed to take place in the year 2017. This is in line with expectations in the availability of new spectrum set out in EU and US policies. In the case of fixed networks, the objectives set in the baseline would require to change the OLTs to increase the capacity provided by the feeder optic fibres in 2020 .

For the evolution of user adoption, this paper utilises a model based on s-shaped growth. S-curve models have proven to provide the most robust fit in estimating the adoption of telecom technologies in the long term (Cardenas, Garcia-Molina, Sales, \& Capmany, 2004) when compared to other models such as time series. In this paper, a simple logistic curve is 
Table 5

User allocation strategies determined for the different zones and population of each of them according to the Spanish demographic scenario.

\begin{tabular}{|c|c|c|c|c|c|c|c|c|c|c|c|c|}
\hline & $\begin{array}{l}\text { Density zone } \\
\text { Population in the zone according to demographic data } \\
\text { (inhabitants) }\end{array}$ & $\begin{array}{l}\boldsymbol{I} \\
2,707,360\end{array}$ & $\begin{array}{l}\text { II } \\
6,300,119\end{array}$ & $\begin{array}{l}\text { III } \\
3,832,203\end{array}$ & $\begin{array}{l}\text { IV } \\
8,596,709\end{array}$ & $\begin{array}{l}V \\
5,016,333\end{array}$ & $\begin{array}{l}\text { VI } \\
11,326,891\end{array}$ & $\begin{array}{l}\text { VII } \\
3,574,008\end{array}$ & $\begin{array}{l}\text { VIII } \\
4,406,394\end{array}$ & $\begin{array}{l}\boldsymbol{I X} \\
668,735\end{array}$ & $\begin{array}{l}\boldsymbol{X} \\
317,055\end{array}$ & $\begin{array}{l}\text { Total } \\
46,745,807\end{array}$ \\
\hline \multicolumn{2}{|c|}{ Coverage strategy selected for the model (Strategy $H$ ) } & \multicolumn{11}{|c|}{$\begin{array}{l}\text { Following this strategy, operators would first deploy networks in higher density zones and when the each density zone reaches } \\
\text { its maximum target coverage next one is started to be covered }\end{array}$} \\
\hline & Deployment and filling sequence & 1 & 2 & 3 & 4 & 5 & 6 & 7 & 8 & 9 & 10 & \\
\hline \multirow[t]{3}{*}{ Fixed networks } & Target coverage (\% of premises) & $100 \%$ & $100 \%$ & $90 \%$ & $80 \%$ & $76 \%$ & $70 \%$ & $50 \%$ & $50 \%$ & $40 \%$ & $40 \%$ & $76.10 \%$ \\
\hline & 2012 No. of inhabitants per zone & 171,323 & - & - & - & - & - & - & - & - & - & 171.323 \\
\hline & 2020 No. of inhabitants per zone & $1,083,918$ & $2,351,705$ & 963,318 & $2,092,656$ & $1,265,506$ & $2,791,370$ & $1,127,939$ & $1,544,809$ & 291,097 & 142,851 & $13,655,168$ \\
\hline \multirow{3}{*}{$\begin{array}{l}\text { Mobile } \\
\text { networks }\end{array}$} & Target coverage (\% of population) & $125 \%$ & $125 \%$ & $110 \%$ & $110 \%$ & $95 \%$ & $95 \%$ & $85 \%$ & $80 \%$ & $65 \%$ & $65 \%$ & $101.96 \%$ \\
\hline & 2012 No. of inhabitants per zone & $3,384,200$ & $7,560,143$ & $4,215,423$ & $9,456,380$ & 200,051 & - & - & - & - & - & $248,16,233$ \\
\hline & 2020 No. of inhabitants per zone & $3,384,200$ & $7,875,149$ & $4,215,423$ & $9,456,380$ & $4,765,516$ & $10,760,546$ & $3,037,907$ & $3,525,115$ & 434,678 & 174,882 & $47,629,797$ \\
\hline \multicolumn{2}{|c|}{ Strategy variation (Strategy $L$ ) } & \multicolumn{11}{|c|}{$\begin{array}{l}\text { This strategy variation proposes to first deploy the network in lower density zones, according to the filling order stated in the } \\
\text { next cell }\end{array}$} \\
\hline & Deployment and filling sequence & 10 & 9 & 8 & 7 & 6 & 5 & 4 & 3 & 1 & 2 & \\
\hline \multirow[t]{3}{*}{ Fixed networks } & Target coverage (\% of premises) & $90 \%$ & $90 \%$ & $65 \%$ & $65 \%$ & $70 \%$ & $70 \%$ & $85 \%$ & $85 \%$ & $90 \%$ & $90 \%$ & $76.12 \%$ \\
\hline & 2012 No. of inhabitants per zone & - & - & - & - & - & - & - & - & 171.323 & - & 171,323 \\
\hline & 2020 No. of inhabitants per zone & $1,075,430$ & $2,351,705$ & 963,318 & $2,092,656$ & $1,265,506$ & $2,91,370$ & $1,127,939$ & $1,544,809$ & 291,097 & 151,340 & $13,655,168$ \\
\hline \multirow{3}{*}{$\begin{array}{l}\text { Mobile } \\
\text { networks }\end{array}$} & Target coverage (\% of population) & $110 \%$ & $110 \%$ & $100 \%$ & $95 \%$ & $100 \%$ & $100 \%$ & $105 \%$ & $105 \%$ & $105 \%$ & $100 \%$ & $101.93 \%$ \\
\hline & 2012 No. of inhabitants per zone & - & - & - & $2,355,958$ & $4,765,516$ & $10,760,546$ & $3,037,907$ & $3,304,796$ & 40.241 & 190,233 & $24,816,233$ \\
\hline & 2020 No. of inhabitants per zone & $3,352,997$ & $7,875,149$ & $4,215,423$ & $9,456,380$ & $4,765,516$ & $10,760,546$ & $3,037,907$ & $3,525,115$ & 434,678 & 206,086 & $47,629,797$ \\
\hline
\end{tabular}




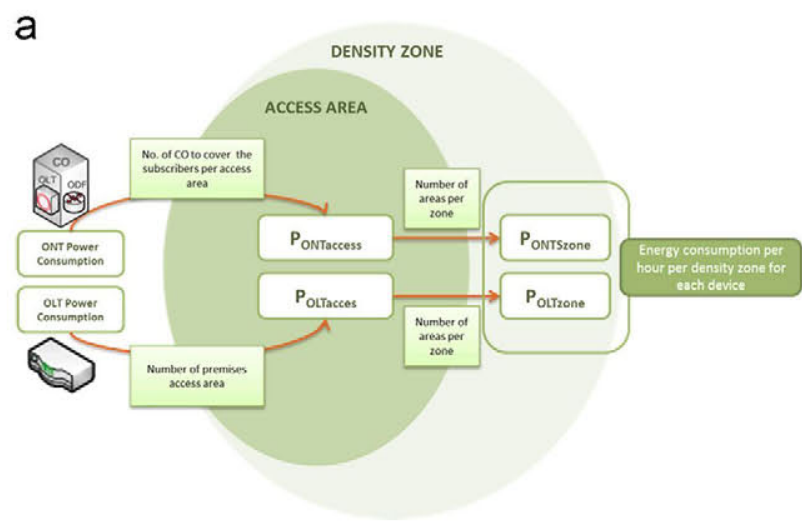

\section{C}
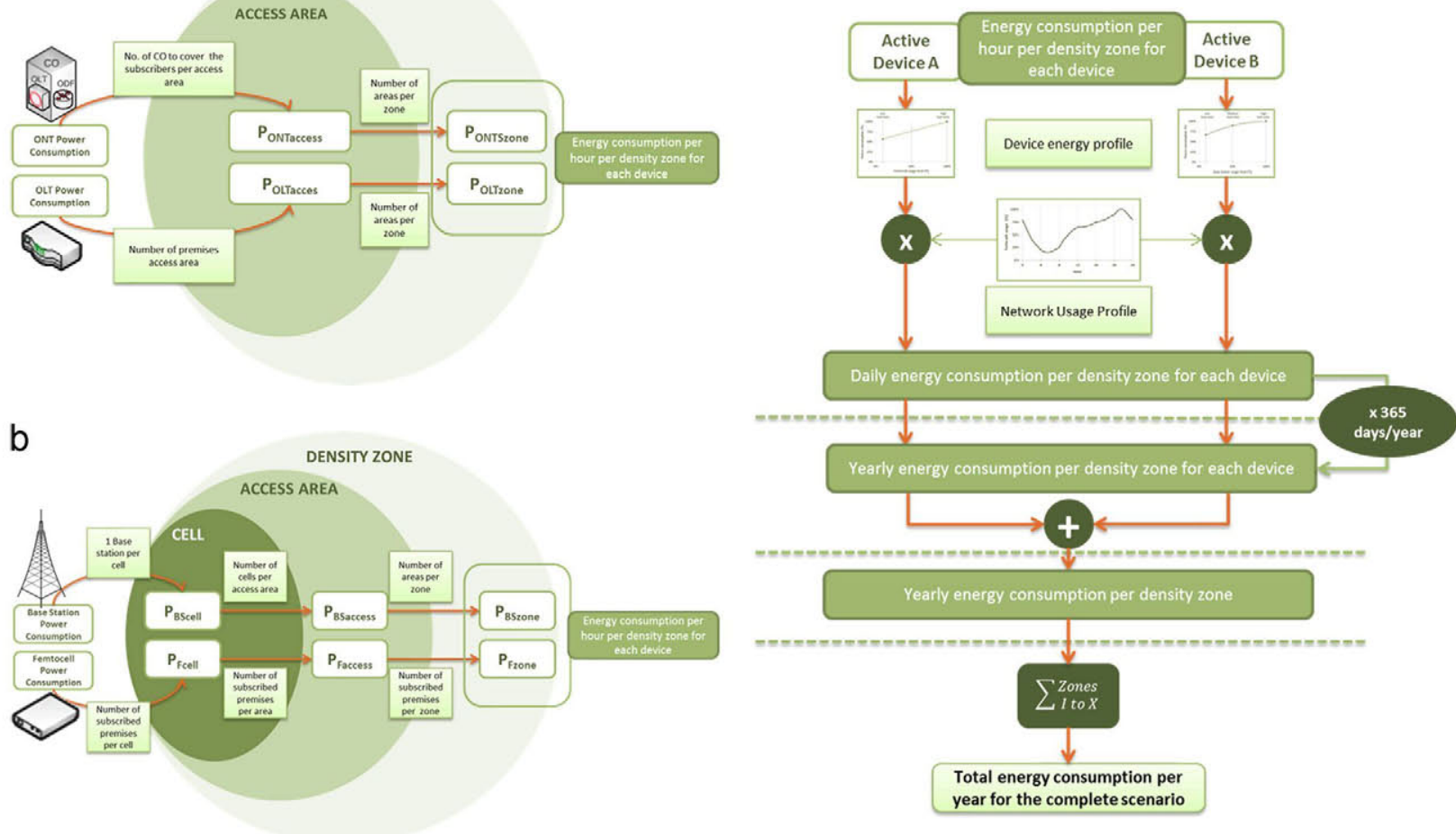

Fig. 5. Calculation process stages: (a) fixed network average hourly energy consumption, (b) mobile network average hourly energy consumption, and (c) daily average, yearly and global scenario energy consumption calculation

Table 6

Spanish user device market, 2011.

Source: Telefónica (2012).

\begin{tabular}{llll}
\hline Device market in $\mathbf{2 0 1 2}$ & $\begin{array}{l}\text { Number of units } \\
\text { (millions) }\end{array}$ & $\begin{array}{l}\text { Penetration of the device among } \\
\text { population (\%) }\end{array}$ & $\begin{array}{l}\text { Number of devices per } \\
\text { premise }\end{array}$ \\
\hline $\begin{array}{l}\text { Laptops } \\
\text { Computers }\end{array}$ & 22.92 & 49 & 1.28 \\
$\begin{array}{l}\text { Other devices (video games consoles, smart } \\
\quad \text { TV, etc.) }\end{array}$ & 22.57 & 48 & 1.26 \\
$\begin{array}{l}\text { Smartphones } \\
\text { Tablets }\end{array}$ & 24.84 & 22 & 0.57 \\
Router & 4.81 & 38 & 0.99 \\
Total & 10.52 & 10 & 0.27 \\
\hline
\end{tabular}

Table 7

Power consumption and usage features of user devices in 2011.

Source: Obtained from specifications of manufacturers and vendors of devices.

\begin{tabular}{llllll}
\hline User devices consumption features 2011 & $\boldsymbol{t}_{\text {usage }}(\mathbf{h})$ & $\boldsymbol{P}_{\text {usage }}(\mathbf{W h})$ & $\boldsymbol{t}_{\text {recharge }}(\mathbf{h})$ & $\boldsymbol{P}_{\text {recharge }}(\mathbf{W h})$ & $\boldsymbol{n}_{\text {recharge }}(\mathbf{p e r}$ day) \\
\hline Laptops & 5 & 60 & 2 & 25 & 0.4 \\
Computers & 3 & 120 & - & - & - \\
Other devices (video games consoles, smart $\mathbf{T V}, \ldots)$ & 1 & 150 & - & - & - \\
Smartphones & - & - & 1 & 5 & 1 \\
Tablets & - & - & 5 & 10 & 0.25 \\
Router & 24 & 11 & - & - & - \\
\hline
\end{tabular}

preferred due to its easy interpretation. Therefore, for fixed and mobile technologies, their penetration is expressed as

$$
f(t)=\frac{M}{1+e^{-\alpha\left(t-T_{0}\right)}}
$$


Table 8

Results of the forecast for the evolution of fixed and mobile technologies in Spain for 2020.

\begin{tabular}{|c|c|c|c|}
\hline Technology & Year & 2012 & 2020 \\
\hline \multirow[t]{4}{*}{ FTTH-GPON } & Fixed BB penetration (lines per premises) & $68.27 \%$ & $79.08 \%$ \\
\hline & FTTH penetration (over total Fixed BB) & $1.47 \%$ & $98.12 \%$ \\
\hline & FTTH penetration (per 100 inhabitants) & $0.99 \%$ & $30.34 \%$ \\
\hline & Number of FTTH lines (millions) & 0.46 & 14.18 \\
\hline \multirow[t]{4}{*}{ LTE } & Mobile penetration (subscribers per 100 inhabitants) & $121.06 \%$ & $128.47 \%$ \\
\hline & LTE penetration (over total mobile penetration) & $40.71 \%$ & $79.80 \%$ \\
\hline & LTE penetration (per 100 inhabitants) & $49.28 \%$ & $102.51 \%$ \\
\hline & Number of mobile BB lines (millions) & 23.54 & 47.74 \\
\hline
\end{tabular}

Table 9

Forecast of user devices for year 2020.

\begin{tabular}{|c|c|c|c|}
\hline Device market in 2020 & $\begin{array}{l}\text { Number of units } \\
\text { (millions) }\end{array}$ & $\begin{array}{l}\text { Penetration of the device among } \\
\text { population }(\%)\end{array}$ & $\begin{array}{l}\text { Number of devices per } \\
\text { premise }\end{array}$ \\
\hline Laptops & 34.60 & 74 & 1.97 \\
\hline Computers & 35.13 & 75 & 1.96 \\
\hline $\begin{array}{l}\text { Other devices (video games consoles, smart } \\
\text { TV, etc.) }\end{array}$ & 15.55 & 33 & 0.87 \\
\hline Smartphones & 47.63 & 102 & 2.65 \\
\hline Tablets & 12.72 & 27 & 0.71 \\
\hline Router & 13.76 & 29 & 0.77 \\
\hline Total & 159.40 & 341 & 8.88 \\
\hline
\end{tabular}

In this equation, $M$ defines the market saturation level, $T_{0}$ is the year when $50 \%$ of the saturation level is reached, and $\alpha$ defines the rate of growth of the curve. The final market saturation levels have been already set in the section above in both fixed and mobile technologies in 2020, and $T_{0}$ and $\alpha$ are obtained by fitting the data about actual Spanish market values for each market (see 2009-2012 figures in Table 12 in Appendix), as explained in the following.

In the case of fixed networks, the forecast uses two estimations: first, the evolution of the market saturation level starting from the current penetration of fixed broadband lines, and then secondly, the share of FTTH technologies in the broadband market. The combination of both estimations results in the evolution of FTTH lines until 2020. Mobile penetration assessment follows a similar pattern. In the first stage, the evolution of the total number of mobile subscribers is estimated, and in the second stage, the number of smartphones with broadband capabilities is estimated with regard to the total number of subscribers. The results of the forecast are summarised in Table 8 (and detailed in the 2013-2020 figures of Table 12 in Appendix).

The evolution of user demand is synergic with changes in the user devices market. In fact, according to forecasts (CISCO, 2012b; Jefferies, 2011), the increase in data traffic, especially in the mobile domain, is driven by the increase in the number of wireless devices that provide access to broadband services. Thus, for 2016, there is the likelihood of data traffic from wireless devices (61\%) exceeding wired device traffic (39\%), while in 2011, wired devices accounted for $55 \%$ of all traffic.

Currently in Spain, each inhabitant has on average nearly two different devices to access the network, and there are nearly five devices per premise (see Table 6). This figure places Spain at the same level that the world average (CISCO, 2012b). Without the appearance of a new technology/device (as experienced in recent years with the entry of tablets into the market), the number of devices is not expected to dramatically increase. For fixed access devices (computers, laptops and others), the increase in penetration is assumed to be gradually lower due to the migration towards wireless devices and the virtualization of a relevant part of the services delivered by these types of devices (Gartner, 2012). Mobile devices will grow according to the forecast of the S-shaped growth explained above. The same logic is followed to establish the number of tablets, as the other main source of data traffic for $4 \mathrm{G}$ networks, apart from the off-loading to fixed networks. The number of router devices relates to the evolution of the penetration of FTTH technology (see above). Following these assumptions Table 9 summarises the projection of the number of user devices for the year 2020 (see the detailed projections for the complete period 2012-2020 in Table 13 in Appendix).

Deployment progress has a considerable impact on the total energy consumption of networks. The distribution of subscribers for the starting and ending point of the analysis in each zone, according to the demand evolution, is shown in Table 5. The table details two different possible strategies for the deployment. The first strategy considers the "rational" approach discussed previously, deploying the network beginning with the zones with the highest population densities. The second strategy is the exact opposite, with the deployment starting in the zones with the lowest population densities. This strategy relates to situations in which licensing or regulatory conditions are imposed to avoid the exclusion in network deployment plans of more isolated zones, where investment per subscriber is higher. This second approach allows for 
Table 10

Power consumption and usage features of user devices for 2020.

Source: Own estimations based on EC (2011).

\begin{tabular}{|c|c|c|c|c|c|}
\hline User devices consumption features 2020 & $t_{\text {usage }}(\mathbf{h})$ & $P_{\text {usage }}(\mathbf{W h})$ & $t_{\text {recharge }}(\mathbf{h})$ & $P_{\text {recharge }}(\mathbf{W h})$ & $\boldsymbol{n}_{\text {recharge }}$ (per day) \\
\hline Laptops & 7 & 45 & 1 & 20 & 0.33 \\
\hline Computers & 2 & 100 & - & - & - \\
\hline other devices (video games consoles, smart $T V, \ldots$ ) & 2 & 125 & - & - & - \\
\hline Smartphones & - & - & 1 & 4 & 0.5 \\
\hline Tablets & - & - & 2.5 & 8 & 0.2 \\
\hline Router & 24 & 20 & - & - & - \\
\hline
\end{tabular}

comparisons between the two extreme deployment possibilities and is used in the sensitivity analysis that is discussed later. In either case, at the end of 2020 , the deployments are meant to be completed regardless of the selected strategy; the differences lie in the energy consumption path.

The evolution of energy consumption in network devices extrapolates existing guidelines for the short term (EC, 2011; ETSI, 2009), where the improvement in energy efficiency performance translates into a modification of the energy profile. In this sense, the change affects both the maximum energy consumed and the percentage of this value consumed at each load state. Base stations are proposed to reduce 25\% their energy consumption in 2014 as compared to 2011. Assuming the same trend, and also assuming that the base value for 2011 should be increased to consider the use of base stations that make use of higher bandwidth and spectral efficiency, the value of energy consumption in 2017 is set at $900 \mathrm{Wh}$. The other energy states are defined at $58 \%$ for the $50 \%$ workload and at $29 \%$ for the $10 \%$ load. Pico-/femtocells will also follow the trend proposed in the guidelines (EC, 2011), and will consume $4 \mathrm{Wh}$ at their maximum work-cycle, using $77 \%$ of this level at the $10 \%$ load state. Regarding fixed networks, ONTs will consume $4.3 \mathrm{Wh}$ at maximum workload and $3.4 \mathrm{Wh}$ at the $10 \%$ state. At the local exchange, each interface will consume $8 \mathrm{Wh}$ and the OLTs will consume $3.8 \mathrm{Wh}$ plus the cooling requirements, established at $60 \%$ of the device consumption (Cucchietti, 2009).

With respect to user devices, energy management features will improve their energy profiles (Bojic, Podobnik, \& Petric, 2012; CISCO, 2012b; Frenger et al., 2011). The only exception will be routers, as they will manage larger amounts of data, increasing the energy consumed. It has also been considered that the increasing usage of wireless devices will reduce time devoted to other user devices, thus decreasing their total energy consumption (Brandewinder, 2008). The proposed values for the 2020 scenario are shown in Table 10.

\section{Results and discussion}

This section introduces the baseline results for energy consumption and costs. First, the evolution of the energy consumption of each of the access network technologies considered is illustrated. Then, a number of comparisons are made between technologies and between the energy consumed by the network itself and the user devices. Finally, the results of a simple sensitivity analysis of the modification of the main network design parameters are presented. The sensitivity analysis includes a brief discussion of the influence of the deployment strategy of operators on energy consumption.

Fig. 6 displays the energy consumption baseline of each access network, according to the design parameters discussed in the previous two sections. FTTH departs from a low energy consumption of about $28 \mathrm{Gw} /$ year in 2011, consistent with its limited market penetration, and grows according to the s-shaped deployment curve until a mature stage is reached at energy consumption of approximately $745 \mathrm{Gw} /$ year. LTE also departs from a modest energy consumption of $43 \mathrm{Gw} / \mathrm{year}$, but grows more rapidly, due to the rapid adoption of 4G, and peaks in 2016 at $718 \mathrm{Gw} /$ year. From that year onwards, three conflicting forces affect the energy consumption baseline for LTE: the improvements in technology-such as an increase in spectral efficiency and the greater availability of bandwidth-substitution of older technology for more energy-efficient devices, and the continuation of $4 \mathrm{G}$ adoption. In 2020, "mature" energy consumption of $638 \mathrm{Gw} /$ year is reached.

Figs. 7 and 8 summarise and compare the baseline results for both types of NGNs, contrasting the situation in 2012 with that of 2020 and introducing the costs of energy consumption. Beginning with FTTH-GPON, the most interesting result is the significant increase in energy consumption within the network and its associated cost. This is to be expected, as the technology has barely commenced the rollout phase. The situation is rather distinct for mobile broadband. Here, the total energy consumption and its costs increase considerably, but in a much more modest proportion. This is essentially due to the fact that the network supporting mobile broadband was already partially deployed in 2012. If the costs per premise (subscriber) or per person are considered, it is also noteworthy how they decrease for FTTH-GPON, despite the increase in energy prices. The reason for this is that in fixed networks, energy consumption by user devices depends on the number of subscribers served by the network and evolves with this number. In the case of mobile broadband, the evolution of the energy consumption per subscriber is the opposite of that for FTTH-GPON: the cost of energy per subscriber almost quadruples over the period considered, as the network has to scale up to cater to more subscribers and more intense usage, both of which increase the number of base stations and pico-/femtocells and their workload.

Costs per subscriber, per person and total costs are lower in mobile broadband technologies compared to FTTH-GPON at the end of the period $-14 \%$ less if the total cost of energy consumption per year is considered. Interestingly, the case would 

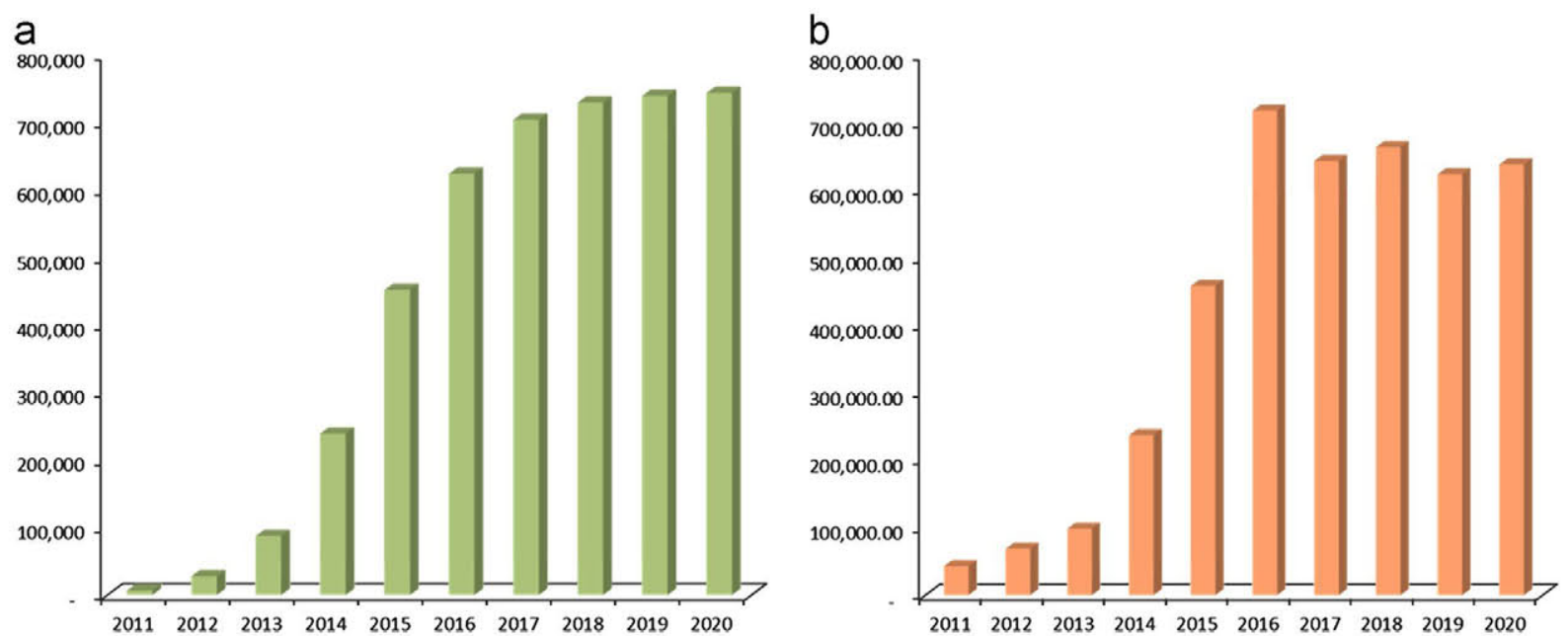

Fig. 6. Energy consumption profiles (MW/year) for the access network consumption along the 2011-2020 period for (a) FTTH-GPON and (b) LTE.

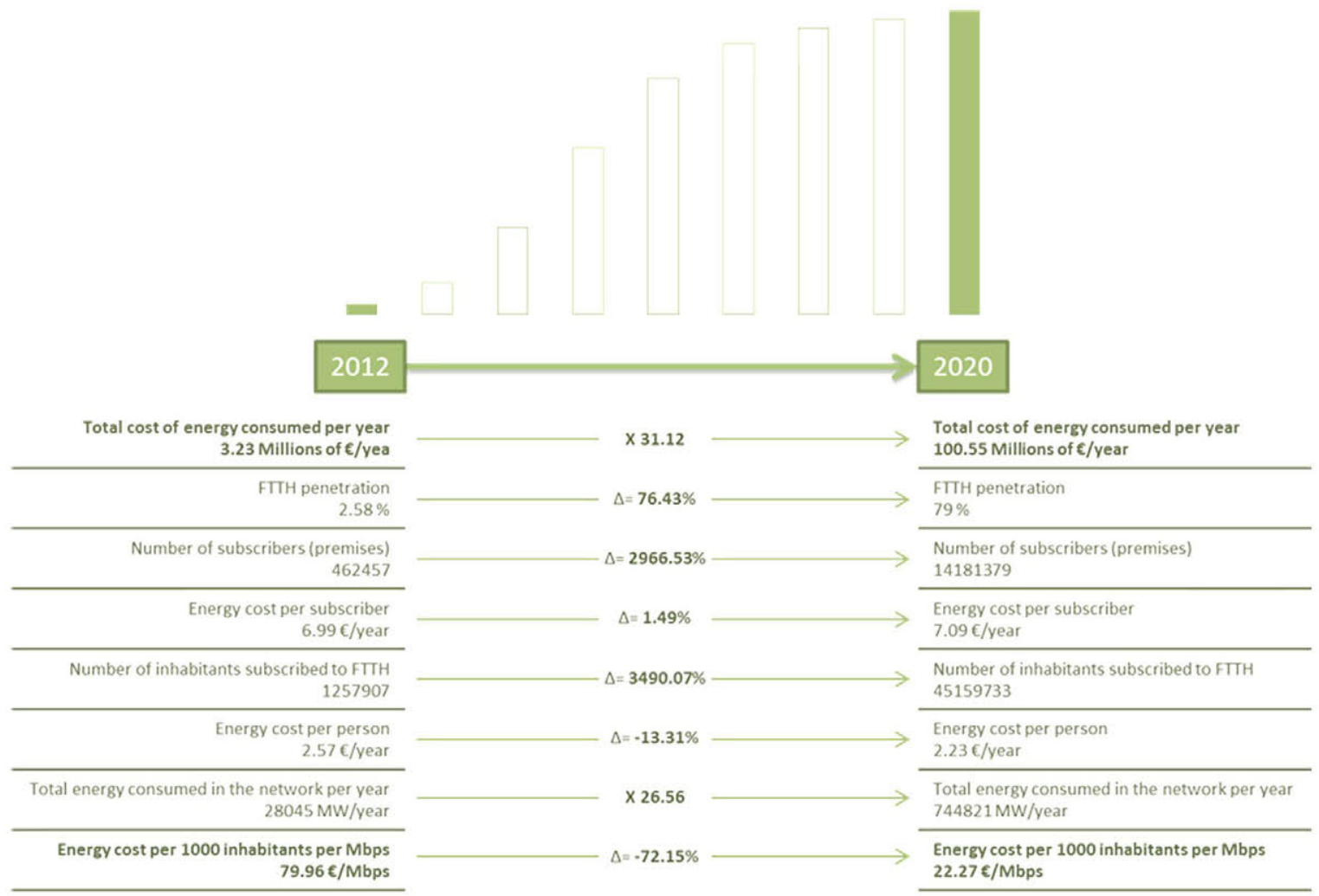

Fig. 7. Baseline results-energy consumption and costs-for FTTH-GPON in 2012 and 2020.

be completely different without considering improvements in spectral efficiency and an increase in the spectrum bandwidth allocated to mobile operators. Without these improvements, the cost of energy consumption for the LTE network in 2020 would be $€ 205.8$ million, more than two times the cost of the energy consumed in the mobile broadband baseline scenario. Finally, a completely different perspective is obtained when the amount of broadband provided by the two different technologies is included. In this case, the energy cost per Mbps is approximately sixteen times less in FTTH than it is for mobile broadband technologies in 2020.

To complete the portrait of energy consumption costs, Fig. 9 compares these energy costs with operating expenses. See Feijoo and Gómez-Barroso (2013) for details on the calculation of the latter. In 2020, the annual energy cost as a percentage of operating expenses is $7.5 \%$ for LTE, nearly double the percentage for FTTH-GPON, at $3.8 \%$. 


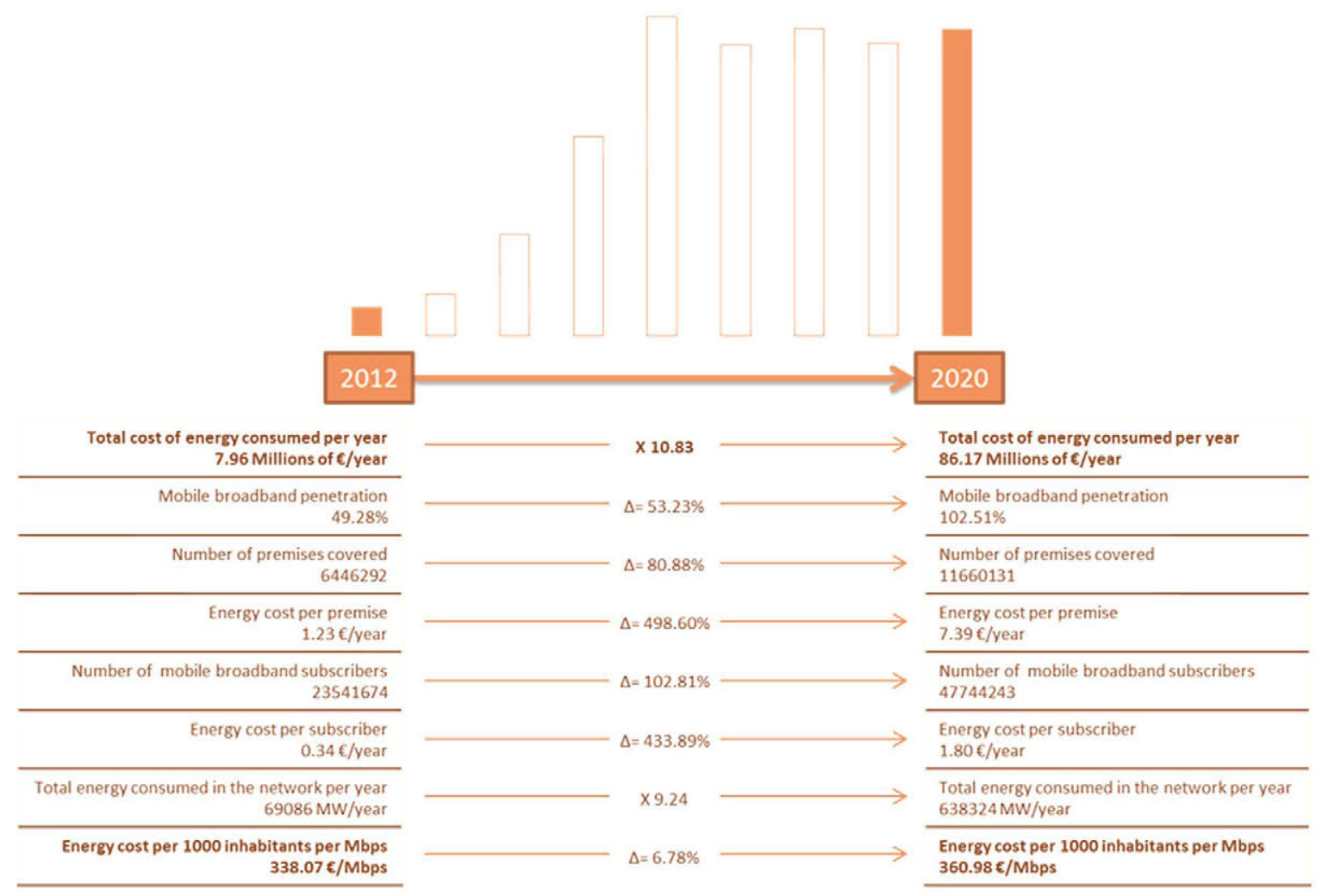

Fig. 8. Baseline results-energy consumption and costs-for LTE in 2012 and 2020.

a

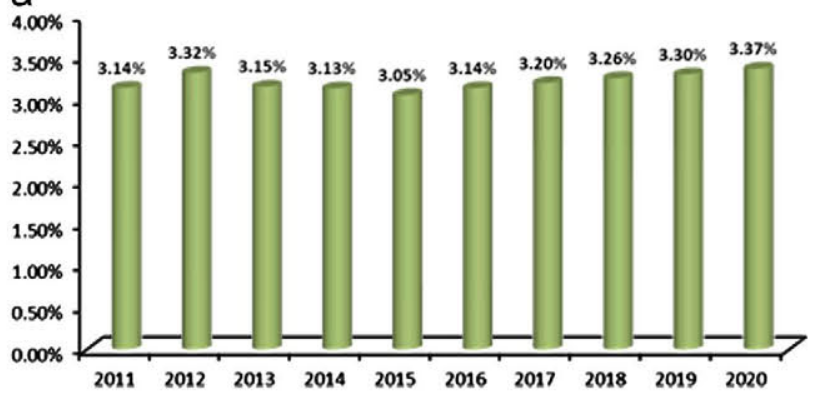

b

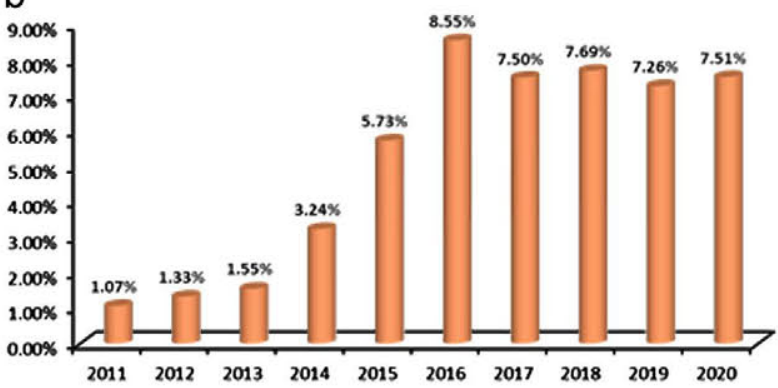

Fig. 9. Percentage of annual energy cost compared to operating expenses in the period 2011-2020 in (a) FTTH-GPON and (b) mobile broadband.

Fig. 10 compares the baseline results of the costs of energy consumption within the NGNs with those of user devices. When comparing network consumption and user devices, there are again important differences between fixed and mobile technologies. User devices typically attached to fixed broadband networks are projected to consume almost seven times more energy than the network itself in 2020. In the mobile broadband case, the network and device energy consumption levels and cost levels are projected to be closer, both at the start of the analysis period in 2012, when devices consumption cost is $11 \%$ higher, and in year 2020 , when it is $18 \%$ higher. The total aggregated usage of fixed and mobile networks with respect to the breakdown of traffic between the two types of networks-Wi-Fi offloading considered-is depicted in Fig. 9c. While the cost of energy consumed by NGNs was 5.17 times lower than that consumed by user devices in 2012 , this ratio is projected to decrease slightly, to 4.95 , by 2020, indicating in both cases the predominance of energy consumption (and cost) associated with user devices. It is also worth noting that while routers are responsible for about $10 \%$ of fixed user device consumption, this proportion increases to $70 \%$ in the case of mobile user devices via traffic off-loading.

When the calculations are performed per subscriber (Fig. 11), the situation is logically the same: "plugged" user devices consume more than their wireless counterparts in terms of network consumption, and the device portion of the aggregated cost for users due to energy consumption is considerably higher than the network energy consumption. The ratio of device to network energy consumption is projected to increase slightly between 2012 and 2020, although it is still projected to remain five times higher. 
a

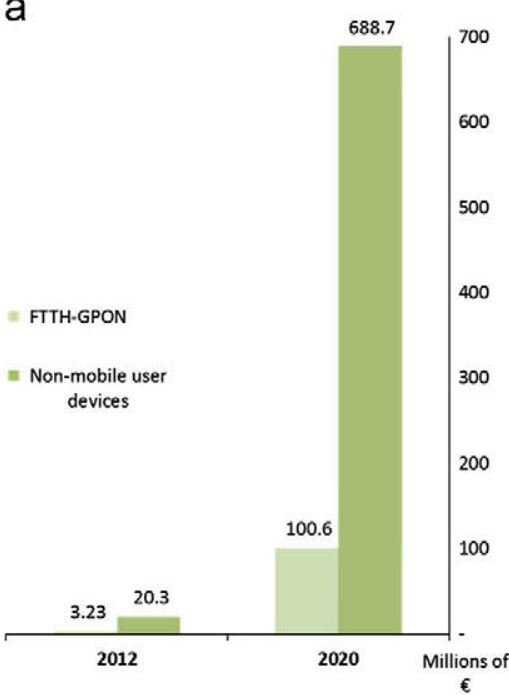

b

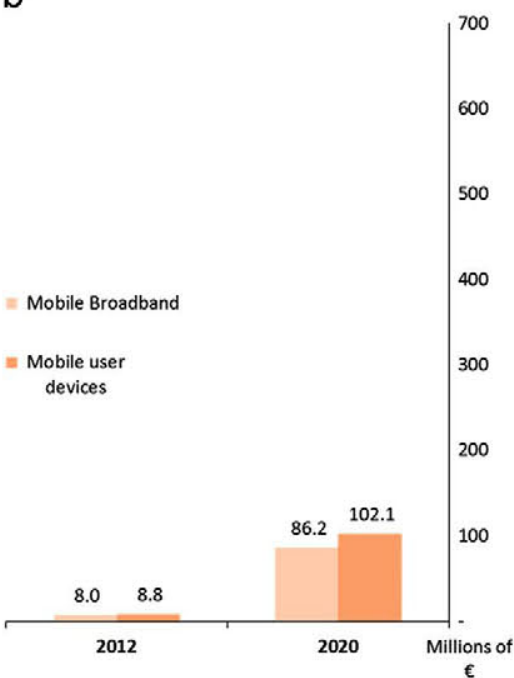

C

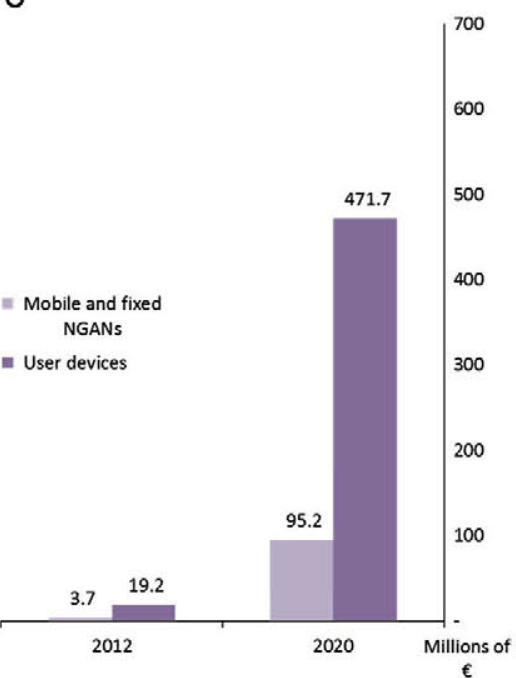

Fig. 10. Cost of energy consumption (M€) in 2012 and 2020 in (a) FTTH-GPON vs. non-mobile devices (b) mobile broadband vs. mobile devices and (c) fixed and mobile NGNs vs. user devices.

a

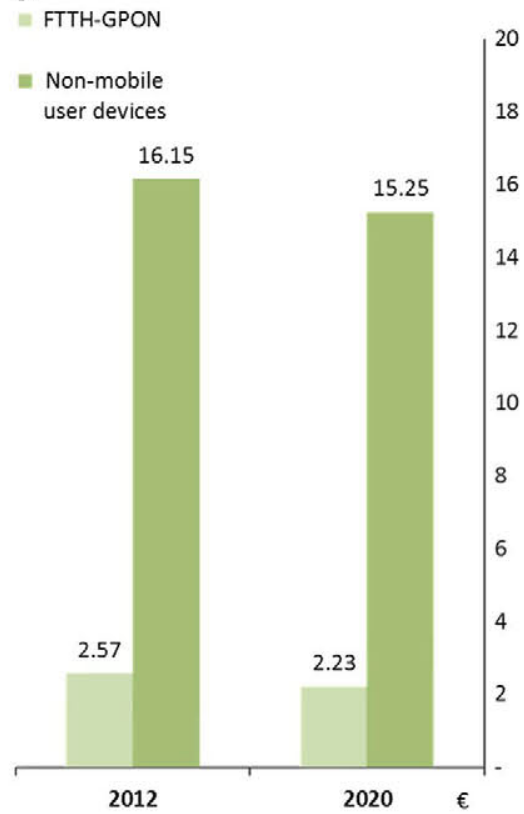

b

$$
\begin{gathered}
\text { Mobile } \\
\text { Broadband } \\
\text { Mobile user } \\
\text { devices }
\end{gathered}
$$

C

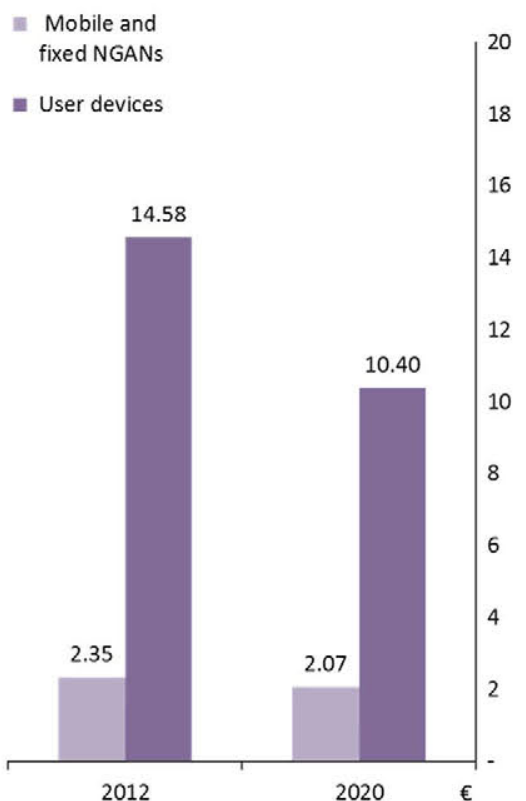

Fig. 11. Cost of energy consumption per subscriber (€) in 2012 and 2020 in (a) FTTH-GPON vs. non-mobile devices, (b) mobile broadband vs. mobile devices and (c) fixed and mobile NGNs vs. user devices.

The final part of this section presents the results of a simple analysis of the changes in energy consumption and cost due to different modifications of the baseline assumptions, creating alternative scenarios. The comparisons are presented in Table 11 for the total energy consumption costs over the full 2012-2020 period.

The analysis shows that for each $1 \%$ annual increase in energy prices, the overall cost of the energy consumed increases by approximately $5 \%$ compared to the baseline. In terms of operating expenses, each $1 \%$ annual increase in energy costs increases the weight of energy consumption in the overall operating expenses of fixed networks by $0.2 \%$ and by $0.4 \%$ in the case of mobile networks, as the latter are more sensitive to energy consumption.

The deployment strategy also has a considerable impact on energy costs, particularly for mobile broadband. In fact, due to regulatory conditions or the influence of public subsidisation, the deployment may begin in a lower-density area. In this situation, mobile broadband consumption in 2012 would be 7.8 times higher. However, the difference between the two 
Table 11

Variations from the baseline for total energy consumption costs for 2012-2020 in access networks for alternative assumptions.

\begin{tabular}{|c|c|c|c|}
\hline \multirow[t]{2}{*}{ Alternative assumption } & & \multicolumn{2}{|c|}{$\begin{array}{l}\text { Variation of energy } \\
\text { cost from baseline (\%) }\end{array}$} \\
\hline & & $\begin{array}{l}\text { FTTH- } \\
\text { GPON }\end{array}$ & LTE \\
\hline Costs of energy & $\begin{array}{l}\text { Remain constant } \\
\text { Increase } 1 \% \text { annually } \\
\text { Increase } 2 \% \text { annually } \\
\text { Increase } 3 \% \text { annually } \\
\text { Increase } 4 \% \text { annually }\end{array}$ & $\begin{array}{l}-10 \% \\
-5 \% \\
0 \% \\
\text { (Baseline) } \\
5 \% \\
11 \%\end{array}$ & $\begin{array}{l}-10 \% \\
-5 \% \\
0 \% \\
\text { (Baseline) } \\
5 \% \\
11 \%\end{array}$ \\
\hline Deployment strategy & $\begin{array}{l}\text { From high to low density } \\
\text { From low to high density }\end{array}$ & $\begin{array}{l}0 \% \\
\text { (Baseline) } \\
4 \%\end{array}$ & $\begin{array}{l}0 \% \\
\text { (Baseline) } \\
40 \%\end{array}$ \\
\hline Device energy enhancements & $\begin{array}{l}\text { According to guidelines } \\
\text { Half the goal of guidelines } \\
\text { No enhancements at all }\end{array}$ & $\begin{array}{l}0 \% \\
\text { (Baseline) } \\
9 \% \\
23 \%\end{array}$ & $\begin{array}{l}0 \% \\
\text { (Baseline) } \\
11 \% \\
51 \%\end{array}$ \\
\hline Market penetration limit & $\begin{array}{l}+10 \% \\
-10 \%\end{array}$ & $\begin{array}{l}9 \% \\
-11 \%\end{array}$ & $\begin{array}{l}12 \% \\
-11 \%\end{array}$ \\
\hline Guaranteed data rates $(\mathrm{QOS})$ & $\begin{array}{l}\text { Reaching } 100 \mathrm{Mbps} \text { in fixed networks in } 2017 \\
\text { Not reaching } 100 \mathrm{Mbps} \text { in } 2020 \text { (staying at } 50 \mathrm{Mbps} \text { in fixed } \\
\text { networks from } 2016 \text { onwards) } \\
\text { Staying at } 3 \mathrm{Mbps} \text { in mobile networks from } 2015 \text { onwards } \\
\text { Staying at } 2 \mathrm{Mbps} \text { in mobile networks from } 2013 \text { onwards }\end{array}$ & $\begin{array}{l}0.4 \% \\
-0.0 \% \\
- \\
-\end{array}$ & $\begin{array}{l}- \\
- \\
-17 \% \\
-30 \%\end{array}$ \\
\hline Access area footprint (in no. of subscribers) & $\begin{array}{l}+200 \% \\
+100 \% \\
+50 \%\end{array}$ & $\begin{array}{l}-0.4 \% \\
-1.4 \% \\
-1.3 \%\end{array}$ & $\begin{array}{l}- \\
- \\
-\end{array}$ \\
\hline $\begin{array}{l}\text { Improvements in GPON technology (from } 2017 \\
\text { onwards) }\end{array}$ & $\begin{array}{l}10 \mathrm{~Gb} / \mathrm{s} \text { fibre feeders } \\
40 \mathrm{~Gb} / \mathrm{s} \text { fibre feeders }\end{array}$ & $\begin{array}{l}0 \% \\
\text { (Baseline) } \\
-1.3 \%\end{array}$ & $\begin{array}{l}- \\
-\end{array}$ \\
\hline BW allocated (from 2017 onwards) & $\begin{array}{l}\text { No additional spectrum } \\
10 \mathrm{MHz} \text { additional spectrum } \\
20 \mathrm{MHz} \text { additional spectrum } \\
30 \mathrm{MHz} \text { additional spectrum } \\
40 \mathrm{MHz} \text { additional spectrum }\end{array}$ & $\begin{array}{l}- \\
- \\
- \\
- \\
-\end{array}$ & $\begin{array}{l}52 \% \\
17 \% \\
0 \% \\
\text { (Baseline) } \\
-10 \% \\
-17 \%\end{array}$ \\
\hline Spectral efficiency (max.) (from 2017 onwards) & $\begin{array}{l}15 \mathrm{~b} / \mathrm{s} / \mathrm{Hz} \\
20 \mathrm{~b} / \mathrm{s} / \mathrm{Hz}\end{array}$ & - & $\begin{array}{l}17 \% \\
0 \% \\
\text { (Baseline) }\end{array}$ \\
\hline $\begin{array}{l}\text { Improvements in management systems of mobile } \\
\text { communications }\end{array}$ & $\begin{array}{l}\text { Switching off } 1 \text { in } 4 \text { base stations by night } \\
\text { Switching off } 1 \text { in } 3 \text { base stations by night }\end{array}$ & - & $\begin{array}{l}-11 \% \\
-14 \%\end{array}$ \\
\hline
\end{tabular}

strategies over the full analysis period would be $40 \%$. This difference shows that, while in both strategies the deployment is near completion at the end of the period, the profile of energy expenditure is very different as it progresses towards the final stage.

Improvements in the energy efficiency of network devices is another area of particular interest. Not achieving the goals set in the guidelines (and their extrapolation for the baseline) would increase the costs of energy consumption by $23 \%$ for fixed NGNs and by $51 \%$ for mobile ones, demonstrating again the greater sensitivity of the latter to energy consumption. Even if the guidelines are only partially met and it takes twice as long to reach the goals originally specified, energy efficiency improvements still yield considerable advantages, as the costs would only increase $9 \%$ for FTTH-GPON and $11 \%$ for mobile broadband.

The effect of variations on the penetration in the market in 2020 is almost proportional to the $10 \%$ margin for both technologies.

Alternative scenarios of the QoS offered by operators are particularly relevant for prospective techno-economic roadmaps. The sensitivity analysis shows two plausible scenarios for FTTH and another two for mobile broadband. In the case of FTTH, complying with the policy goal of achieving $100 \mathrm{Mbps}$ from 2017 onwards instead of the 2020 goal signifies a very minor increase in energy consumption, while not achieving it and maintaining a 50-Mbps level has negligible effects in terms of the overall cost of energy consumed. In the case of mobile broadband, only scenarios with less ambitious goals 
were selected for consideration. Again, mobile technologies were found to be much more sensitive to variations in the costs of energy consumption, reducing it up to $30 \%$, for instance when only $2 \mathrm{Mbps}$ are offered to subscribers with some guarantee.

The next two situations of interest pertain specifically to FTTH-GPON. The first addresses the possibility of increasing the footprint-the access area-of a fibre-based local exchange. Due to the capacity of fibres and their lack of need for repeaters, it is possible to cover a larger area from the position of a local exchange, in fact suppressing some other location and saving in facilities expenses. Doubling the access area reduces the cost of energy consumption by $1.4 \%$. From this level of coverage upwards, the savings in energy due to the reduction in local exchanges start to be balanced with the increase in the number of OLT and the energy they use, reducing the overall effect and eventually reversing it. The second specific scenario for FTTH addresses improvements in the technology for fibre feeders. The impact of increasing the data rate is also relatively modest, with a decrease in the cost of energy consumption of 1.3\% when technology is replaced from 2017 onwards. In both cases, the main reason for the modest decrease lies in the limited share of energy consumption due to OLTs-the devices involved in feeder fibre data rates-about 8 to $11 \%$ of the annual energy consumption in the access network for the baseline.

For the mobile technologies, three different situations were analysed. The most relevant effect pertains to bandwidth allocated to mobile operators. Not having access to the $20 \mathrm{MHz}$ of additional spectrum used in the baseline from 2017 on would mean an increase of $52 \%$ in the energy consumption cost. The effect of additional spectrum on energy consumption is clearly not linear, with the greatest impact being associated with the first $10 \mathrm{MHz}$ allocated to operators, which saves $35 \%$ of energy costs. The next $10 \mathrm{MHz}$ would save an additional 17\%, with the third and fourth $10 \mathrm{MHz}$ saving an additional $10 \%$ and $7 \%$ respectively. The impact of spectral efficiency is also considerable. Not using this technological improvement from 2017 onwards would mean a $17 \%$ increase in energy costs. The combination of some of these effects is non-linear. For instance, without additional spectrum and without improvements in spectral efficiency, the cost would rise by up to $86 \%$. The third situation examines improvements in the management of the mobile network, such as switching off base stations in areas where there are overlaps of coverage and at times of low traffic workload. This situation could represent the interest of a single operator or even "energy-aware cooperative management of the cellular access networks of the operators that offer service over the same area" (Ajmone Marsan \& Meo, 2011). In relatively ambitious scenarios, this could reduce energy consumption by $11 \%$ to $13 \%$.

Finally, with regard the sensitivity analysis of user devices, if the evolution proposed in terms of energy efficiency does not take place for fixed devices, energy costs would increase by up to $43 \%$. This effect would be $24 \%$ in the case of mobile devices.

\section{Conclusions}

Energy considerations have played a very limited role in the planning, management and regulation of NGNs. This seems incomprehensible, considering that broadband networks are the centre of any policy or strategy for boosting economic development and as "the establishment of ultra-high-speed networks is often seen as the basis for realisation of the great potential for social and economic change related to ICT" (Røpke, 2012). If the future is to be sustainable and NGNs are to have a role to play in that future, then the energy consumption of NGNs-and its related cost-must not be overlooked. In the case of operators, energy consumption costs have a direct impact on their operating expenses, but promoting sustainable innovation strategies could become an import criterion for stakeholders beyond the mere business plan. In addition, citizens are ever more conscious of their role in the building of the society, trying to add their two cents to making it more sustainable. For many of them, energy-saving aspects are becoming a factor to be considered in consumption decisions, at least for some product and services. Although this behaviour has not yet been shown to extend to telecoms, from the authors' perspective, it is worth of exploration, if only to increase user awareness of the energy relevance in the NGN domain.

In fostering a discussion about the energy efficiency of telecommunications networks, this article has introduced a model for the assessment of the energy consumed by access networks and user devices in a practical setting. The resulting baseline hints at both technological, strategic and policy enhancements that could be implemented to reduce the level of energy consumption by NGNs. This model can also serve as a benchmark for other developments not considered in the paper, such as deeper modifications to network topology, new modulation schemes and protocols and further variations to network management systems as suggested in the technical literature (Ajmone Marsan \& Meo, 2011; López Vizcaíno et al., 2012). As there was no relevant real data available for comparison with the results obtained, the assumptions in the baseline were given special relevance to ease replicability, and the conclusions below are based on relative variations and not on absolute figures.

In any case, to achieve a higher degree of energy efficiency, the obvious first solution is to improve the energy profiles of the devices used in the network rollout. This can be accomplished through a continuation of existing policies concerning energy-efficient network devices. In fact, this paper proposes an extension of the existing guidelines until 2020. Also, although there was an obvious effect projected to result from increasing the energy efficiency of network devices, their precise impact in the deployment of main NGN access technologies remains largely unexplored. The analysis of the baseline quantifies the costs of the absence of such guidelines, providing a foundation for further policy making and highlighting two important points: the relevance these developments have in the mobile domain and the positive impact of achieving, as quickly as possible, the goals established in the guidelines. 
Nonetheless, with respect to user devices, the baseline shows that reductions in the energy consumption of user devices would have a much greater impact than increasing the efficiency of network devices, in addition to the benefit of reducing direct energy costs of users. In this regard, while there are specific guidelines for a roadmap on the energy efficiency of network devices, there are no equivalent specifications on the user device side with similar broad industry agreement. This is, therefore, an area of policy making with industry support. Routing equipment appears to be a main target of energy efficiency improvements, because its key role in managing both fixed data traffic and off-loading of mobile data traffic.

The baseline also shows that other factors that influence energy consumption in the network portion could have an even greater influence than energy consumption by active devices. In particular, the technological features of networks, such as the spectral efficiency and frequency bandwidth allocated to mobile operators, strategic decisions such as QoS, market penetration, and the size and order of coverage for areas in the deployment can substantially influence energy consumption and its evolution over the period leading up to 2020. The effects of these technological developments and strategic decisions have been neglected in assessments of energy efficiency and sustainability perspective, despite the fact that they could have a huge influence. The case of frequency bandwidth allocated to mobile operators is particularly relevant: it is the factor with the single greatest influence on the costs of energy consumption, although it is seldom, or if at all, mentioned among the motivations for freeing spectrum and harmonising spectrum-related policies. The proposed baseline quantifies the precise effect of additional spectrum on energy savings, permitting a detailed assessment of policies in this field. In addition, within the mobile domain, improvements in spectral efficiency and management of cellular systems have considerable impact, suggesting research goals (for private companies and public bodies) with a measurable impact on sustainability and, in the case of management systems, providing an incentive for a different type of infrastructure sharing among operators.

In fact, and in general, deviations from the baseline have more consequences for mobile networks; fixed networks are less sensitive to deviations that may occur, for example, when considering changes in the deployment strategy to cater to rural areas, changes in the QoS, or even when specific modifications in the fixed technology or topology of the network are considered. The reason behind this lesser sensitivity is simple. The energy consumption of fixed networks depends basically on the ONT at the consumer premises, and its evolution remains stable except when energy guidelines are not followed, while the energy consumption of mobile networks is basically dependent on the number of base stations and their features, parameters that are extensively modified in alternative scenarios. As a consequence, in fixed networks, the key element for further improvements is the ONT, which can be modified without major changes in the network design. However, in mobile networks, the critical element is the design of the network itself and its main component, the base station, both of which are linked with a priori strategic decisions for operators.

Overall policy has a considerable influence. Some key parameters of networks design depend on regulatory decisions, such as the portion of the available spectrum allocated to operators. Policy influences the rollout strategies of access networks in a number of ways, licence conditions and subsidies being two prominent examples. Moreover, guidelines for energy efficiency depend on policy initiatives to gather industry support. Furthermore, policies establish roadmaps for research into energy-efficient technologies. Last but not least, energy policies affect the cost of energy consumption in ultrabroadband networks and thus retail prices for consumers. In each of these policies it is possible to pursue more sustainable avenues, e.g., increasing spectrum allocation to mobile operators, balancing licence conditions with measures to save energy, influencing industry compliance with guidelines for energy efficiency in network and user devices and including more specific sustainability goals in research and development public programmes. As a particular instance of the lack of policy action in public institutions regarding energy consumption in telecommunications networks, it can be mentioned that "IEA is aware of the importance of energy consumption related to running the ICT infrastructure [...] but no specific policies are suggested ..." (Røpke, 2012).

When considering energy consumption on the user side in particular, the results show that the energy used in fixed networks is higher than in mobile networks, within the baseline described. However, if the cost of energy per subscriber per Mbps is considered, FTTH-GPON is considerably more efficient, such that, from this perspective, this technology is more sustainable. The energy consumption of user devices is considerably greater than that of the network. This is arguably the most interesting result of this paper. It is usually accepted that energy usage in ICTs is shared in three relatively similar proportions between servers, networks and devices (ITU, 2007; Sutherland, 2009). However, the evolution of NGNs will modify this balance, reducing the energy consumption share of networks and proportionally increasing that of devices. Along the same lines, IEA indicates that global residential electricity consumption by ICT equipment grew by nearly $7 \%$ per annum between 1990 and 2008, and even with foreseen improvements in energy efficiency, consumption from electronics is projected to increase by $250 \%$ by 2030 (IEA, 2009). All of these results underscore the relevance of implementing technical, economic and policy strategies that do not discourage the use of ultra-broadband technologies but rather make them more energy efficient, including the energy consumption of user devices in the equation.

A final point to be made is that consumers tend to lack information about the energy impact of their increasing usage of networks and devices and the associated costs and effects on sustainability. In other words, they do not have a key piece of information that they need to make informed decisions. This lack of information conflicts with the rise of a new class of consumers who make conscious and knowledgeable choices. Against this background, this paper has attempted to place energy considerations in the forefront of the debate and has shown that providing transparent information to consumers on their usage of ICT networks and devices is feasible and relevant. 
Table 12

Penetration of broadband lines for the Spanish scenario. Source: CMT

\begin{tabular}{|c|c|c|c|c|c|c|c|c|}
\hline \multirow[t]{2}{*}{ Year } & \multicolumn{5}{|l|}{ Fixed broadband data } & \multicolumn{3}{|l|}{ Mobile broadband data } \\
\hline & Fixed broadband lines & $\begin{array}{l}\text { Penetration over } \\
\text { the total number of } \\
\text { premises }(\%)\end{array}$ & $\begin{array}{l}\text { Number of FTTH } \\
\text { subscribers }\end{array}$ & $\begin{array}{l}\text { Penetration rate over } \\
\text { the total number of } \\
\text { premises }(\%)\end{array}$ & $\begin{array}{l}\text { Market share } \\
\text { over } \\
\text { total fixed BB } \\
\text { lines }(\%)\end{array}$ & $\begin{array}{l}\text { Penetration over the } \\
\text { total population }(\%)\end{array}$ & $\begin{array}{l}\text { Number of devices } \\
\text { (millions) }\end{array}$ & $\begin{array}{l}\text { Penetration of Smartphone } \\
\text { devices over the total } \\
\text { population (\%) }\end{array}$ \\
\hline \multicolumn{9}{|c|}{ Actual Spanish market values } \\
\hline 2009 & $9,799,486$ & 51.3 & 10,192 & 0.06 & 0.10 & 108.36 & 7.81 & 15.64 \\
\hline 2010 & $10,649,632$ & 55.4 & 35,586 & 0.20 & 0.33 & 111.45 & 9.91 & 19.55 \\
\hline 2011 & $11,164,966$ & 59.7 & 110,168 & 0.61 & 0.99 & 118.76 & 17.85 & 34.69 \\
\hline 2012 & $12,254,117$ & 61.8 & 462,457 & 2.58 & 3.77 & 121.06 & 24.84 & 49.13 \\
\hline \multicolumn{9}{|c|}{ Forecasted values } \\
\hline 2013 & $12,791,003$ & 64.3 & $1,561,602$ & 8.70 & 12.21 & 122.78 & 30.07 & 63.20 \\
\hline 2014 & $13,203,947$ & 67.8 & $4,360,613$ & 24.29 & 33.03 & 124.19 & 35.83 & 75.62 \\
\hline 2015 & $13,515,408$ & 70.6 & $8,597,913$ & 47.90 & 63.62 & 125.33 & 40.30 & 85.37 \\
\hline 2016 & $13,746,876$ & 72.9 & $11,837,494$ & 65.95 & 86.11 & 126.26 & 43.41 & 92.29 \\
\hline 2017 & $13,917,012$ & 74.6 & $13,311,474$ & 74.16 & 95.65 & 127.01 & 45.42 & 96.85 \\
\hline 2018 & $14,041,058$ & 76.0 & $13,863,205$ & 77.23 & 98.73 & 127.61 & 46.64 & 99.72 \\
\hline 2019 & $14,130,965$ & 78.7 & $14,080,022$ & 78.44 & 99.64 & 128.09 & 47.35 & 101.47 \\
\hline 2020 & $14,195,850$ & 79.08 & $14,181,379$ & 79.00 & 99.90 & 128.47 & 47.74 & 102.51 \\
\hline
\end{tabular}


Table 13

Evolution of the number of user devices according to forecasting assumption for the 2011-2020 period.

Source: Obtained from specifications of manufacturers and vendors of devices.

\begin{tabular}{|c|c|c|c|c|c|c|c|c|c|}
\hline Device evolution (millions of units) & 2012 & 2013 & 2014 & 2015 & 2016 & 2017 & 2018 & 2019 & 2020 \\
\hline Computer & 22.36 & 22.59 & 23.04 & 23.73 & 24.68 & 25.91 & 27.47 & 29.39 & 31.74 \\
\hline Laptop & 22.71 & 22.93 & 23.39 & 24.09 & 25.06 & 26.31 & 27.89 & 29.84 & 32.23 \\
\hline Video console & 10.05 & 10.15 & 10.36 & 10.67 & 11.09 & 11.65 & 12.35 & 13.21 & 14.27 \\
\hline Smartphone & 26.53 & 35.03 & 42.54 & 48.63 & 53.13 & 56.25 & 58.35 & 59.74 & 60.67 \\
\hline Tablet & 4.77 & 6.30 & 7.65 & 8.74 & 9.55 & 10.11 & 10.49 & 10.74 & 10.91 \\
\hline Router & 10.52 & 13.89 & 16.87 & 19.28 & 21.07 & 22.31 & 23.14 & 23.69 & 24.06 \\
\hline Total & 96.95 & 110.90 & 123.85 & 135.15 & 144.58 & 152.54 & 159.68 & 166.62 & 173.88 \\
\hline
\end{tabular}

\section{Acknowledgements}

This research had been developed thanks to the funding of the STAREBEI-Programme from the European Investment Bank (EIB). This paper does not in any way represent EIB's official position in regard to the matters here exposed.

The authors would also like to thank the editors and the anonymous reviewers for their valuable comments and suggestions on earlier drafts.

\section{Appendix. Tables and data}

See Tables 12 and 13.

\section{References}

3GGPP. (2012). 3GPP TR 25.913. Requirements for evolved UTRA and evolved UTRAN.

Ajmone Marsan, M., \& Meo, M. (2011). Energy efficient wireless Internet access with cooperative cellular networks. Computer Networks, 55(2), 386-398, http://dx.doi.org/10.1016/j.comnet.2010.10.017.

Ali, I., Rehman, K. U., Yilmaz, A. K., Nazir, S., \& Ali, J. F. (2010). Effects of corporate social responsibility on consumer retention in the cellular industry of Pakistan. African Journal of Business Management, 4(4), 475-485.

Analysys Mason. (2008). The costs of deploying fibre-based next-generation broadband infrastructure. London. Final report for the Broadband Stakeholder Group.

Analysys Mason. (2009). Competitive models in GPON. London. Ofcom.

Andrews, J. G., Claussen, H., Dohler, M., Rangan, S., \& Reed, M. C. (2012). Femtocells: Past, present, and future. IEEE Journal on Selected Areas in Communications, 30(3), 497-508.

Astely, D., Dahlman, E., Furuskar, A., Jading, Y., Lindstrom, M., \& Parkvall, S. (2009). LTE: The evolution of mobile broadband. Communications Magazine, IEEE, 47(4), 44-51.

Baliga, J., Ayre, R., Sorin, W.V., Hinton, K., \& Tucker, R.S. (2008, 24-28 Feb. 2008). Energy consumption in access networks. Paper presented at the conference on optical fibre communication/National Fibre Optic Engineers Conference, 2008. OFC/NFOEC 2008.

Bock, C., Chanclou, P., Finochietto, J. M., Franzl, G., Hajduczenia, M., \& Koonen, T., et al. (2008). Architecture of future access networks. In J. Prat (Ed.), Nextgeneration FTTH Passive Optical Networks. Research Towards Unlimited Bandwidth Access (pp. 5-46). Netherlands: Springer.

Bojic, I., Podobnik, V., \& Petric, A. (2012). Swarm-oriented mobile services: Step towards green communication. Expert Systems with Applications, 39(9), 7874-7886, http://dx.doi.org/10.1016/j.eswa.2012.01.120.

Bolla, R., Bruschi, R., Davoli, F., \& Cucchietti, F. (2011). Energy efficiency in the future internet: A survey of existing approaches and trends in energy-aware fixed network infrastructures. Communications Surveys \& Tutorials, IEEE, 13(2), 223-244, http://dx.doi.org/10.1109/surv.2011.071410.00073.

Brandewinder, M. (2008). S-shaped market adoption curve. From 〈http://www.clear-lines.com/blog/post/S-shaped-market-adoption-curve.aspx〉.

Cardenas, A., Garcia-Molina, M., Sales, S., \& Capmany, J. (2004). A new model of bandwidth growth estimation based on the gompertz curve: Application to optical access networks. Journal of Lightwave Technology, 22(11), 2460-2468, http://dx.doi.org/10.1109/jlt.2004.834495.

CELTIC-Plus. (2011). Multilink Architecture for Multiplay Services (MARCH). From 〈http://projects.celtic-initiative.org/march/march/index.php〉.

CISCO. (2012a). Cisco Visual Networking Index: Global Mobile Data Traffic Forecast Update, 2011-2016.

CISCO. (2012b). Entering the Zettabyte era.

Coomonte, R., Lastres, C., Feijóo, C., \& Martín, Á. (2012). A simplified energy consumption model for fibre-based Next Generation Access Networks. Telematics and Informatics, 29(4), 375-386, http://dx.doi.org/10.1016/j.tele.2011.11.005.

Cucchietti, F. (2009). Energy efficiency in TLC networks: The operator and the user perspective. Italy: Parma.

Cuomo, F., Cianfrani, A., Polverini, M., \& Mangione, D. (2012). Network pruning for energy saving in the Internet. Computer Networks, 56(10), 2355-2367, http://dx.doi.org/10.1016/j.comnet.2012.03.009.

Dahlman, E., Ekstrom, H., Furuskar, A., Jading, Y., Karlsson, J., Lundevall, M., et al. (2006, 7-10 May 2006). The 3G long-term evolution-radio interface concepts and performance evaluation. Paper presented at the IEEE 63rd Vehicular Technology Conference, 2006. VTC 2006-Spring.

Deruyck, M., Tanghe, E., Joseph, W., \& Martens, L. (2011). Modelling and optimization of power consumption in wireless access networks. Computer Communications, 34(17), 2036-2046, http://dx.doi.org/10.1016/j.comcom.2011.03.008.

Diaz-Rainey, I., \& Ashton, J. K. (2011). Profiling potential green electricity tariff adopters: Green consumerism as an environmental policy tool?. Business Strategy and the Environment, 20(7), 456-470, http://dx.doi.org/10.1002/bse.699.

EC. (2009). EU energy trends to 2030. Brussels. European commission, Directorate-General for Energy in collaboration with Climate Action DG and Mobility and Transport DG.

EC. (2010a). A digital agenda for Europe. Brussels. European Commission, COM(2010) 245.

EC. (2010b). Energy 2020. A strategy for competitive, sustainable and secure energy, COM(2010) 639 final.

EC. (2011). Code of Conduct on Energy Consumption of Broadband Equipment version 4: European Commission, Institute for the Environment and the Sustainability.

EC. (2012). Digital Agenda Scoreboard 2012. European Commission.

ETSI. (2009). TS 102 706. Environmental Engineering (EE). Energy Efficiency of Wireless Access Network Equipment. 
Feijoo, C., \& Gómez-Barroso, J.-L. (2013). El despliegue de redes de acceso ultrarrápidas: un análisis prospectivo de los límites del mercado. Papeles de Economía Española, 136, 116-130.

Feijóo, C., Gómez-Barroso, J.-L., \& Ramos, S. (2011). An analysis of next generation access networks deployment in rural areas. Paper presented at the FITCE 2011. Palermo (Italy).

Fibre to the Home Council Europe. (2012). FTTH Handbook Creating a brighter future. Retrieved from 〈http://www.ftthcouncilmena.org/documents/Reports/ FTTH-Handbook-2012-V5.0-English.pdf).

Forge, S., Blackman, C., \& Bohlin, E. (2005). The demand for future mobile communications markets and services in Europe. Institute for Prospective Technological Studies-JRC-EC.

Forsgren, A., \& Prytz, M. (2006). Telecommunications network design. In M. C. Resende, \& P. Pardalos (Eds.), Handbook of Optimization in Telecommunications (pp. 269-290). US: Springer.

Frenger, P., Moberg, P., Malmodin, J., Jading, Y., \& Godor, I. (2011, 15-18 May 2011). Reducing energy consumption in LTE with cell DTX. Paper presented at the 2011 IEEE 73rd vehicular technology conference (VTC Spring).

Furuskar, A., Jing, R., Blomgren, M., \& Skillermark, P. (2011, Feb. 28 2011-March 3 2011). LTE and HSPA for fixed wireless broadband: Datarates, coverage, and capacity in an Indian rural scenario. Paper presented at the 2011 2nd international conference on wireless communication, vehicular technology, information theory and aerospace \& electronic systems technology (Wireless VITAE).

Gartner. (2012). Gartner says the personal cloud will replace the personal computer as the center of users' digital lives by 2014. From 〈http://www.gartner.com/ it/page.jsp?id=1947315

Ghosh, A., Mangalvedhe, N., Ratasuk, R., Mondal, B., Cudak, M., \& Visotsky, E., et al. (2012). Heterogeneous cellular networks: From theory to practice. Communications Magazine, IEEE, 50(6), 54-64, http://dx.doi.org/10.1109/mcom.2012.6211486.

Gómez-Barroso, J., \& Robles-Rovalo, A.. (2008). Wireless hopes for universal service in developing countries: An assessment of the Mexican context. Info, 10 (5-6), 83-91.

Gómez-Barroso, J. L., \& Feijóo, C. (2010). Volition versus feasibility: State aid when aid is looked upon favourably: The broadband example. European Journal of Law and Economics, 1-18, http://dx.doi.org/10.1007/s10657-010-9159-x.

GSA. (2013). Evolution to LTE report. Global mobile Suppliers Association, March, 2013.

IDATE. (2012). DigiWorld Yearbook 2012. The challenges of digital world. Montpellier, France: IDATE.

IEA. (2009). Gadgets and Gigawatts. Policies foR ENERGY EFFICIENT ELEctronics. Paris, France.

ITU-R. (2008). Requirements related to technical performance of IMT-Advanced radio interface(s). ITU,ITU-R M.2134.

ITU. (2007). ICTs and climate change.

ITU. (2008a). NGNs and energy efficiency.

ITU. (2008b). Recommendation ITU-T G.984.1- Gigabit-capable passive optical networks (GPON): General characteristics.

ITU. (2010). ITU World Radiocommunication Seminar highlights future communication technologies. Focus on international regulations for spectrum management and satellite orbits. From 〈http://www.itu.int/net/pressoffice/press_releases/2010/48.aspx〉.

Ixia. (2011). Quality of Service (QOS) and Policy Management in Mobile Data Networks.

Jeanjean, F. (2010). Financing the next generation infrastructures. Consumer subsidies or infrastructure subsidies? Paper presented at the EuroCPR 2010. Brussels.

Jefferies. (2011). Mobility 2020 how an Increasingly Mobile World will Transform TMT Business Models over the Coming Decade. Global TMT Team.

Jukan, A., \& Mambretti, J. (2012). Evolution of optical networking toward rich digital media services. Proceedings of the IEEE, 100(4), 855-871, http://dx.doi. org/10.1109/jproc.2011.2182076.

Keymile. (2011). FTTH/FTTB: Point to Point vs. PON [Power Point Presentation].

Kolk, A., \& van Tulder, R. (2010). International business, corporate social responsibility and sustainable development. International Business Review, 19(2), 119-125, http://dx.doi.org/10.1016/j.ibusrev.2009.12.003.

Kramer, G., De Andrade, M., Roy, R., \& Chowdhury, P. (2012). Evolution of optical access networks: Architectures and capacity upgrades. Proceedings of the IEEE, 100(5), 1188-1196, http://dx.doi.org/10.1109/jproc.2011.2176690.

López Vizcaíno, J., Ye, Y., \& Tafur Monroy, I. (2012). Energy efficiency analysis for flexible-grid OFDM-based optical networks. Computer Networks, 56(10), 2400-2419, http://dx.doi.org/10.1016/j.comnet.2012.03.012.

Lluch, J. (2012). The importance of "small cells" in future mobile networks. From 〈http://blogthinkbig.com/la-importancia-de-las-small-cells-en-las-redes-mo viles-futuras $\lambda$

Malmodin, J., Oliv, L., \& Bergmark, P. (2001). Life cycle assessment of third generation (3G) wireless telecommunication systems at Ericsson. Paper presented at the Proceedings EcoDesign 2001: second international symposium on environmentally conscious design and inverse manufacturing, 2001.

McDonald, S., Oates, C., Thyne, M., Alevizou, P., \& McMorland, L.-A. (2009). Comparing sustainable consumption patterns across product sectors. International Journal of Consumer Studies, 33(2), 137-145, http://dx.doi.org/10.1111/j.1470-6431.2009.00755.x.

Melody, W.H (2007). Markets and policies in new knowledge economies. In R. Mansell, C. Avgerou, D. Quah, \& R Silverstone (Eds.), The Oxford Handbook of Information and Communication Technologies (pp. 55-74). Oxford: Oxford University Press.

Murugesan, S. (2008). Harnessing green IT: Principles and practices. IT Professional, 10(1), 24-33, http://dx.doi.org/10.1109/mitp.2008.10.

Ozaki, R. (2011). Adopting sustainable innovation: What makes consumers sign up to green electricity?. Business Strategy and the Environment, 20(1), 1-17, http://dx.doi.org/10.1002/bse.650.

Radio, N., Ying, Z., Tatipamula, M., \& Madisetti, V. K. (2012). Next-generation applications on cellular networks: Trends, challenges, and solutions. Proceedings of the IEEE, 100(4), 841-854, http://dx.doi.org/10.1109/jproc.2011.2182092.

Raychaudhuri, D., \& Mandayam, N. B. (2012). Frontiers of wireless and mobile communications. Proceedings of the IEEE, 100(4), 824-840, http://dx.doi.org/ $10.1109 /$ jproc.2011.2182095.

Reading, H. (2011). FTTH Worldwide Market \& Technology Forecast, 2006-2011. USA.

Røpke, 1. (2012). The unsustainable directionality of innovation-The example of the broadband transition. Research Policy, 41(9), 1631-1642, http://dx.doi. org/10.1016/j.respol.2012.04.002.

Scharnhorst, W., Hilty, L. M., \& Jolliet, 0. (2006). Life cycle assessment of second generation $(2 \mathrm{G})$ and third generation (3G) mobile phone networks. Environment International, 32(5), 656-675, http://dx.doi.org/10.1016/j.envint.2006.03.001.

Schindler, F., Sadhir, V., Robbins, B., Guo, D., \& Paradis, J. (2011). Wireless data connectivity with LTE power amplifiers. Microwave Journal (Nov 2011 Supplement), 6-10.

Shi, L, Chowdhury, P., \& Mukherjee, B. (2013). Saving energy in long-reach broadband access networks: Architectural approaches. Communications Magazine, IEEE, 51(2), S16-S21, http://dx.doi.org/10.1109/mcom.2013.6461184.

Stall-Meadows, C., \& Hebert, P. R. (2011). The sustainable consumer: An in situ study of residential lighting alternatives as influenced by infield education. International Journal of Consumer Studies, 35(2), 164-170, http://dx.doi.org/10.1111/j.1470-6431.2010.00987.x.

Sutherland, E. (2009). Climate Change: The Contribution of Telecommunications Communications \& Strategies, 4th Quarter 2009 (No. 76), pp. 61-76.

Telefónica. (2012). eEspaña 2012.

Tselekounis, M., Maniadakis, D., \& Varoutas, D. (2012). NGA Investments: A departure from the existing cost and demand structure assumptions. Paper presented at the 19th Biennial Conference of International Telecommunications Society (ITS 2012).

Vadada, H. (2010). QOS over $4 G$ networks. From 〈http://4gwirelessjobs.com/articles/article-detail.php?QOS-over-4G-networks\&Arid=MTU2\&Auid=MTly〉.

Valenzuela, L., Mulki, J., \& Jaramillo, J. (2010). Impact of customer orientation, inducements and ethics on loyalty to the firm: Customers' perspective. Journal of Business Ethics, 93(2), 277-291, http://dx.doi.org/10.1007/s10551-009-0220-z.

Windrum, P., Ciarli, T., \& Birchenhall, C. (2009). Consumer heterogeneity and the development of environmentally friendly technologies. Technological Forecasting and Social Change, 76(4), 533-551, http://dx.doi.org/10.1016/j.techfore.2008.04.011. 